\title{
Working
}

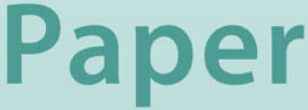


Measuring Oil-Price Shocks Using MarketBased Information

Tao Wu and Michele Cavallo

INTERNATIONAL MONETARY FUND 
This page intentionally left blank

CInternational Monetary Fund. Not for Redistribution 


\title{
IMF Working Paper
}

\author{
IMF Institute
}

\section{Measuring Oil-Price Shocks Using Market-Based Information ${ }^{1}$}

\author{
Prepared by Tao Wu and Michele Cavallo
}

Authorized for distribution by Ling Hui Tan

January 2011

\begin{abstract}
This Working Paper should not be reported as representing the views of the IMF. The views expressed in this Working Paper are those of the author(s) and do not necessarily represent those of the IMF or IMF policy. Working Papers describe research in progress by the author(s) and are published to elicit comments and to further debate.
\end{abstract}

\begin{abstract}
We study the effects of oil-price shocks on the U.S. economy combining narrative and quantitative approaches. After examining daily oil-related events since 1984, we classify them into various event types. We then develop measures of exogenous shocks that avoid endogeneity and predictability concerns. Estimation results indicate that oil-price shocks have had substantial and statistically significant effects during the last 25 years. In contrast, traditional VAR approaches imply much weaker and insignificant effects for the same period. This discrepancy stems from the inability of VARs to separate exogenous oil-supply shocks from endogenous oil-price fluctuations driven by changes in oil demand.
\end{abstract}

JEL Classification Numbers:C32, C82, E31, E32, Q43

Keywords: Oil Shocks, Market-Based Information, VAR Identification

Author's E-Mail Address:twu@imf.org and michele.cavallo@frb.gov

\footnotetext{
${ }^{1}$ For helpful suggestions and comments, we thank Michelle Alexopoulos, Mark Bergen, Martin Eichenbaum, Neil Ericsson, Luca Guerrieri, James Hamilton, Òscar Jordà, Lutz Kilian, Hashem Pesaran, Monika Piazzesi, Trevor Reeve, Christina Romer, David Romer, Eric Swanson; and seminar and conference participants at the Bank of England, Bank of Italy, University of Chicago Booth School of Business, Federal Reserve Banks of Chicago, Dallas, and San Francisco, Federal Reserve Board, the IMF, Oxford University, the 2007 SED Annual Meeting, the 2007 and 2009 NBER Summer Institute, the 2008 SCE Conference, and the 2009 Econometric Society Meetings. Thien Nguyen, Nina Ozdemir, Michael Simmons, and Tiffany Smith provided excellent research assistance. The views expressed in this paper are solely our responsibility and should not be interpreted as reflecting the views of the IMF, the Federal Reserve Board, or the Federal Reserve System in general.
} 


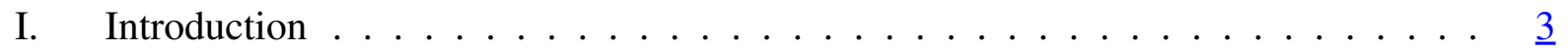

II. Measures of Exogenous Oil-Price Shocks Based on Market Information . . . . . . $\underline{6}$

A. A Comprehensive Study of Daily Oil-Related Events . . . . . . . . . . . . $\underline{6}$

B. Two Measures of Oil-Price Shocks . . . . . . . . . . . . . . . $\underline{8}$

C. What Does Exogeneity Mean? . . . . . . . . . . . . . . . $\underline{9}$

D. Constructing Monthly Oil Shock Series . . . . . . . . . . . . . 11

III. Estimating the Effects of Oil-Price Shocks . . . . . . . . . . . . . . 13

IV. Empirical Results . . . . . . . . . . . . . . . . . . . . . . 15

A. Impulse Responses of Market-Information-Based Exogenous Oil-Price Shocks $\underline{15}$

B. Impulse Responses of VAR-Based Measures of Oil-Price Shocks . . . . . . 16

C. Other Kinds of Oil-Price Shocks Based on Market Information . . . . . . . $\underline{20}$

D. Robustness and Stability . . . . . . . . . . . . . . . $\underline{23}$

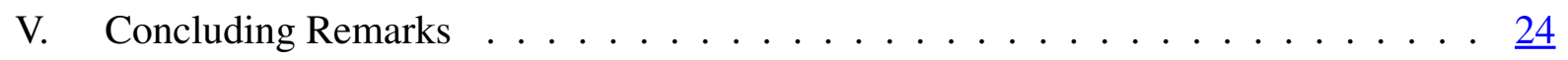

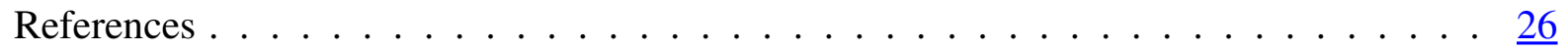

Tables

1. Classification of oil-related events . . . . . . . . . . . . . . . $\underline{29}$

2. Test of the Exogeneity of Oil-Shock Series . . . . . . . . . . . . . . $\underline{\underline{30}}$

3. Robustness and stability checks . . . . . . . . . . . . . . . . . $\underline{31}$

Figures

1. Market-based and VAR-based Measures of Oil Shocks . . . . . . . . . . . . $\underline{32}$

2. Alternative Measures of Exogenous Oil Shocks . . . . . . . . . . . . . . . $\underline{33}$

3. Impulse Responses to Exogenous Oil-Price Shocks . . . . . . . . . . . . . . . . $\underline{34}$

4. VAR-Based Measures . . . . . . . . . . . . . . . . . $\underline{35}$

5. Alternative Estimates of Impulse Responses . . . . . . . . . . . . . . . . . . . . . $\underline{\underline{36}}$

6. Impulse Responses to Oil Demand Changes . . . . . . . . . . . . . . . . . . $\underline{37}$

7. Impulse Responses to OPEC/Non-OPEC Moves . . . . . . . . . . . . . . . . . $\underline{38}$

8. Impulse Responses to Oil Inventory Changes . . . . . . . . . . . . . . . . . . . . . $\underline{\underline{39}}$

9. Impulse Responses to Military Conflicts . . . . . . . . . . . . . . . . . . . . 40

10. Impulse Responses in Sub-sample Periods . . . . . . . . . . . . . . . . . . 41 


\section{INTRODUCTION}

The relationship between oil-price shocks and the macroeconomy has attracted extensive scrutiny by economists over the past three decades. The literature, however, has not reached a consensus on how these shocks affect the economy, or by how much. A large number of studies have relied on vector autoregression (VAR) approaches to identify exogenous oilprice shocks and estimate their effects. Nevertheless, estimation results generally have not provided compelling support for the conventional-wisdom view that following a positive oilprice shock, real GDP declines and the overall price level increases. In addition, the estimated relationship is often unstable over time. This is why, after a careful examination of various approaches, Bernanke, Gertler, and Watson (1997) conclude that "finding a measure of oil price shocks that 'works' in a VAR context is not straightforward. It is also true that the estimated impacts of these measures on output and prices can be quite unstable over different samples."

Traditional VAR-based measures of oil-price shocks exhibit two recurrent weaknesses: endogeneity and predictability. With regard to the first one, VAR approaches often cannot separate oil-price movements driven by exogenous shocks from those reflecting endogenous responses to other kinds of structural shocks. For instance, the oil price increases that occurred over the 2002-2008 period were viewed by many as the result of "an expanding world economy driven by gains in productivity" (The Wall Street Journal, August 11, 2006). The occurrence of such endogenous movements will undoubtedly lead to biased estimates of the effects of oil shocks.

On the other hand, part of the observed oil price changes might have been anticipated by private agents well in advance. Therefore, they can hardly be considered as "shocks." Most measures of oil-price shocks in the literature are constructed using only spot oil prices. However, when the market senses any substantial supply-demand imbalances in the future, changes in the spot prices may not fully reflect such imbalances. A number of authors (e.g., Wu and McCallum, 2005; Chinn, LeBlanc, and Coibon, 2005) have found that oil futures prices are indeed quite powerful in predicting spot oil price movements, indicating that at least a portion of such movements may have been anticipated at least a few months in advance. Both these concerns underscore the need to pursue a different approach to obtain more reliable measures of exogenous oil-price shocks.

In this paper, we combine narrative and quantitative approaches to develop new measures of exogenous oil-price shocks that avoid the endogeneity and predictability concerns. We begin 
by identifying the events that have driven oil-price fluctuations on a daily basis from 1984 to 2007. To achieve this goal, we first collect information from daily oil-market commentaries published in a number of oil-industry trade journals, such as Oil Daily, Oil \& Gas Journal, and Monthly Energy Chronology. This leads to the construction of a database that identifies the oil-related events that have occurred each day since January 1984. We then classify these daily events into a number of different event types based on their specific features, such as weather changes in the U.S., military actions in the Middle East, OPEC announcements on oil production, U.S. oil inventory announcements, etc. (see Table 1). Next, for each event type we construct a measure of oil-price shocks by running oil-price forecasting equations on a daily basis. Finally, shock series from exogenous oil events are selected and aggregated into a single measure of exogenous oil-price shocks. By construction, these shock measures should be free of endogeneity and predictability problems, and statistical tests are also conducted to confirm their exogeneity. For robustness, we also provide a number of alternative definitions of exogenous oil-price shocks and construct corresponding shock measures for each one of them.

We employ our new, market-information based measures to study the responses of U.S. output, consumer prices, and monetary policy to exogenous oil-price shocks. We also compare the estimated responses with those obtained following two traditional VAR-based identification strategies that are very popular in the literature. Estimation results reveal substantial and statistically significant output and price responses to exogenous oil-price shocks identified by our market-based methodology. In contrast, responses implied by the VAR-based approaches are much weaker, statistically insignificant, and unstable over time. Moreover, we find that following a demand-driven oil-price shock, real GDP increases and the price level declines. This finding is consistent with scenarios in which oil-price fluctuations are endogenous responses to changes in the level of economic activity rather than reflecting exogenous oil shocks. We argue that traditional VAR-based approaches cannot separate the effects of these two kinds of shocks and consequently lead to biased estimates of the dynamic responses.

Our approach is similar in spirit to the narrative approach pursued in a number of existing studies. Romer and Romer $(2004,2010)$ adopt it in their analyses of monetary policy and tax shocks, Alexopoulos (2011) and Alexopoulos and Cohen (2009) in the context of technology shocks, and Ramey (2009) in her analysis of government spending shocks. With regard to oil-price shocks, several earlier studies have tried to isolate some geopolitical events associated with abrupt oil-price increases and examine their effects on the U.S. economy. Hamilton (1983, 1985) identifies a number of “oil-price episodes” before 1981, mainly Middle East ten- 
sions, and concludes that such oil shocks had effectively contributed to postwar recessions in the U.S. Hoover and Perez (1994) revise Hamilton's (1983) quarterly dummies into a monthly dummy series and find that oil shocks had led to declines in U.S. industrial production. Bernanke, Gertler, and Watson (1997) construct a quantitative measure, weighting Hoover and Perez's dummy variable by the log change in the producer price index for crude oil, yet they were not able to find statistically significant macroeconomic responses to oil shocks in a VAR setting. Hamilton (2003) identifies five military conflicts during the postwar period and reexamines the effects of the associated oil shocks on U.S. GDP growth. Finally, Kilian (2008) also analyzes six geopolitical events since 1973, five in the Middle East and one in Venezuela, and examines their effects on the U.S. economy. Our study contributes to the literature by constructing a database of all oil-related events on a daily basis. This allows us to identify all kinds of oil shocks and conduct a more comprehensive analysis than earlier studies. Extracting the "unpredictable" component of oil-price fluctuations using an oil futures price-based forecasting model represents another novelty of our work.

More recently, Kilian (2009) has also used information from the oil market to disentangle different kinds of oil-price shocks. In particular, he has constructed an index of global real economic activity, including it in a tri-variate VAR, along with data on world oil production and real oil prices. Using a recursive ordering of these variables, he recovers an oil-supply shock, a global aggregate demand-driven shock, and an oil market-specific demand shock. Although his approach is completely different from ours, the effects on the U.S. economy of all three kinds of structural shocks estimated in his work are quite close to our empirical estimates. This, in turn, corroborates the validity of our approach. We present detailed evidence in subsequent sections.

Our study is also related to the ongoing debate about how the real effects of oil-price shocks have changed over time. For instance, VAR studies, such as those of Hooker (1996) and Blanchard and Galí (2009), have usually found a much weaker and statistically insignificant relationship between their identified oil-price shocks and real GDP growth in the U.S. and other developed economies during the last two to three decades. These results are often cited as evidence suggesting that the U.S. economy has become less volatile and more insulated from external shocks, the result of better economic policy, a lack of large adverse shocks, or a smaller degree of energy dependence (e.g., a more efficient use of energy resources and a larger share of service sector in the U.S. economy), all contributing to a "Great Moderation" starting in the first half of the 1980s. Although we do not challenge this general characterization of the "Great Moderation," our estimation results reveal a substantial and significant adverse effect of exogenous oil shocks on the U.S. economy, even during the last two and a half 
decades. Results from VAR studies, in particular the time variation in coefficient estimates, may simply reflect an inadequate identification strategy.

The rest of our paper is organized as follows. Section II describes the methodology we follow to identify the oil-related events and construct our oil-price shock measures. Section III illustrates the procedure we use to estimate the macroeconomic effects of oil-price shocks. Section IV presents our empirical results and compares them with those of earlier studies. Robustness and stability check is also conducted in this section. Section V offers our concluding remarks.

\section{Measures of Exogenous Oil-Price SHOCKS BASED ON MARKET INFORMATION}

This section describes the construction of our market information-based measures of oil-price shocks. The methodology consists of three key steps. First, for each trading day since 1984, we collect information from various oil-industry trade journals, identify the events that have driven oil-price movements on that day, and classify them into 22 oil-event types. Second, for each event type, we construct measures of oil-price shocks by conducting an oil-price forecasting exercise at a daily frequency, in order to capture the unpredictable component of oilprice fluctuations on each day. Finally, we aggregate shock series corresponding to exogenous event types and construct a single measure of exogenous oil-price shocks. For robustness, we also provide a number of alternative definitions of exogenous oil-price shocks, and for each definition we aggregate the daily shock series of the corresponding event types into a single measure of exogenous shocks.

\section{A. A Comprehensive Study of Daily Oil-Related Events}

The first step of our methodology is to identify the events behind the observed oil-price fluctuations on each trading day. ${ }^{1}$ For this purpose, we collect information from a number of oilindustry trade journals, such as the Oil Daily and the Oil \& Gas Journal. We also cross check the information with other sources, including government publications such as the Monthly

\footnotetext{
${ }^{1}$ To be consistent with both the literature and the terminology in use in the oil industry, throughout the paper we refer to the spot oil price as the price quoted on front-month futures contracts of West Texas Intermediate light sweet crude oil traded on the New York Mercantile Exchange (NYMEX). This is also the spot price that most of the financial press reports every day (see, e.g., The Wall Street Journal).
} 
Energy Chronology, published by the Energy Information Administration (EIA), a statistical agency within the U.S. Department of Energy.

Our sample runs from January 3, 1984, to October 31, 2007, a total of 5,971 trading days. For each trading day in our sample period, we collect information on oil-related events that occurred on that day from the market commentaries and reports published in the above-mentioned trade journals. After a thorough reading of these market commentaries and reviews, we classify oil-related events into 22 different types (see Table 1), such as weather changes in the U.S., military actions in the Middle East, OPEC announcements on oil production, and U.S. oil inventory announcements. Based on this analysis, we assign one numerical code to each trading day, or more than one code if more than one type of oil-related event occurred on the same day.

We conduct the event study at a daily frequency because the oil market, like other well-developed financial markets, is highly volatile and reacts immediately to economic, political, and industryspecific news. Choosing a lower frequency, such as monthly or even weekly, would likely result in a situation in which several events might have happened within the same period, making it difficult to measure the magnitude of the shock that each event brings to the oil market. The daily frequency is the highest frequency for which we could find relevant market information.

To minimize the possibility that both the interpretation of market-based information and the event classification may be biased by the analyst's subjective predispositions, we have conducted a thorough content analysis, a practice widely used in marketing literature (see, e.g., Kassarjian 1977, and Levy, Dutta, and Bergen, 2002). Specifically, three independent analysts have been engaged in reading the documents and classifying the events. The results have been compared to make sure that they are consistent with each other.

Column 3 of Table 1 shows the observed relative frequencies of oil-related events from 1984 to 2007. Excluding the days with no particular reason observed or when the price movement was driven by speculation, the most frequent event is "OPEC announcements on oil production" (741 trading days, 12 percent of the sample), followed by "U.S. oil inventory announcements" (730 days, 12 percent), and "political developments in the Middle East" (476 days, 8 percent). ${ }^{2}$ Oil production or transportation disruptions both in the U.S. and outside the

\footnotetext{
${ }^{2}$ It is well known that OPEC announcements on production quota are not always fully enforced. Therefore, on the day of the news, the reaction of oil prices to these announcements or to related developments (e.g., various rumors) can be viewed as reflecting oil traders' probabilistic assessment of such events on the supply of oil.
} 
U.S. (types 3 and 4) affected oil-price movements on 486 trading days, about 8 percent of the sample. ${ }^{3}$

\section{B. Two Measures of Oil-Price Shocks}

The next step of our methodology is to quantify the magnitude of the shocks implied by each oil event on a daily basis. Two approaches are adopted. The first one is based on a modified version of the oil-price forecasting model in Wu and McCallum (2005). In particular, for each trading day, we regress the realized oil-price changes on the spreads between oil spot and futures prices at different horizons quoted by the end of the previous trading day, with a rolling sample consisting of the previous 200 trading days. ${ }^{4}$ Our estimating equation is:

$$
\log P_{t+1}^{S}-\log P_{t}^{S}=\alpha+\sum_{j=2}^{6} \beta_{j}\left(\log P_{j, t}^{F}-\log P_{t}^{S}\right)+\varepsilon_{t+1},
$$

where $P_{t}^{S}$ and $P_{t+1}^{S}$ are the spot prices at $t$ and $t+1$, respectively, $P_{j, t}^{F}$ denotes the $j$-month oil futures price at time $t, \alpha$ and $\beta_{j}$ 's are the estimation coefficients, and $\varepsilon_{t+1}$ a white-noise error term. We then calculate the unanticipated change in the spot price as realized at $t+1$ and define the "predicting error" as our shock measure for the day.

Equation (1) incorporates term structure information on futures-spot spreads in forecasting future oil-price movements. This equation is in the same spirit as the bond-yield forecasting model in Cochrane and Piazzesi (2002, 2005), who also use information embodied in term spreads of interest rates at all available horizons to forecast future bond-yield movements. Wu and McCallum (2005) compare the out-of-sample forecasting performance of such a "futures-spot spread" model with that of several other models and conclude that the futures-spot spread model performs the best, particularly when the forecasting horizons are within the next few months. On the other hand, we exclude price quotes on oil futures contracts beyond six months from the equation, as the futures market becomes substantially less liquid for those horizons, and consequently the quoted futures prices become a much less accurate measure of oil-price expectations. Wu and McCallum (2005) have also found that the out-of-sample performance of the futures-spot spread model becomes much worse when the forecasting horizon goes beyond one year.

\footnotetext{
${ }^{3}$ Other types of less frequent events include changes in the market's expectations of U.S. oil inventories, U.S. weather changes, and changes in oil demand within and outside the U.S.

${ }^{4}$ Changing the length of the rolling sample has negligible effects on the forecasting results.
} 
Alternatively, we measure the magnitude of the shocks as simply the change in the logarithm of the spot oil price on the day. This quantitative approach is consistent with the belief that oil futures prices do not have any predictive content for future oil prices (Alquist and Kilian, 2010) and that the log oil price follows a random walk. We call the shock measure based on this approach the "log-price change" measure and, in subsequent econometric analysis, use it along with the "predicting error" measure described above. ${ }^{5}$ However, it is important to bear in mind that both measures are formulated on a daily basis and that, through the identification of the oil-related events, they will be constructed around days of exogenous events, implying that both will be legitimate measures of exogenous oil shocks.

\section{What Does Exogeneity Mean?}

Having classified the daily oil-related events and constructed daily shock measures for each event type, the next step is to construct a single series of exogenous oil-price shocks, by combining shock series related to all types of exogenous events. For this purpose, we first need to explicitly define which types of events are truly exogenous.

Ideally, a strictly defined exogenous shock should be exogenous with respect to the U.S. economy in the most rigorous sense. Therefore, any event that could possibly correlate with the U.S. economy cannot be a genuine exogenous shock. For instance, weather changes in New England (event-type 1 in Table 1) do not qualify as exogenous oil shocks, as such changes may affect not only oil demand but also utility output, construction activities, and retail sales. For the same reason, oil production and transportation disruptions in the U.S. (event-type 3) do not qualify as exogenous oil-supply shocks, as the energy industry is a significant component of the U.S. economy. Furthermore, military conflicts (event-types 10 through 12) do not qualify, as they may affect U.S. defense spending. Even when the U.S. is not directly involved, one can still argue that the military buildups following such conflicts would make them correlate with real GDP in addition to their impacts on oil supply and demand (Ramey and Shapiro 1998, Ramey 2009). For the same reason, political developments (event-types 7 through 9) may not qualify as genuine exogenous shocks. These concerns essentially rule out most of the oil-related events that many researchers consider as exogenous. In fact, during the past 25 years, there were only six trading days in which non-U.S. weather changes (event-

\footnotetext{
${ }^{5}$ Hamilton (2009a) has conducted a literature survey, noting that, while many empirical studies "found that the spot oil price provides as good or even a better forecast of the future oil price than does the futures price," they in general also "failed to reject the hypothesis that the oil futures price embodies a rational expectation of the future spot price." Therefore, our decision of running two alternative forecasting models to extract the unpredictable component of oil-price movements is consistent with his conclusion.
} 
type 2) had significantly affected the oil market, and there was no new oil field discovered anywhere (event-types 5 and 6) that had a noticeable impact on the oil market.

In light of these considerations, we take a step back and allow for some degree of ambiguity in our econometric analysis. We reiterate that different assumptions may lead to quite different interpretations of "exogeneity." Therefore, rather than providing one single series and treating it as the exogenous oil shock measure, we provide three definitions of "exogeneity" and construct the corresponding series of exogenous oil-price shocks, ${ }^{6}$ and examine their dynamic macroeconomic effects in the subsequent sections:

(1) Our "baseline" definition consists of event-types 1 through 12, including the U.S. and non-U.S. weather changes, oil production or transportation disruptions, and political and military actions. These are typically the kinds of events that many researchers consider as exogenous. ${ }^{7}$

(2) Alternatively, we formulate a "narrow" definition, consisting of only event-types 2 through 9 , that is, non-U.S. weather changes, oil production or transportation disruptions, and political developments. Compared with our "baseline" specification, this definition excludes U.S. weather changes and military actions around the world. We exclude these events because they are more likely to be correlated with real GDP growth in the U.S.

(3) Finally, our "broad" definition of exogenous oil-related events consists of event-types 1 through 12 and 15 through 17 . This definition includes not only the event types in our baseline definition, but also events such as oil inventory announcements (for instance, the U.S. Energy Information Administration's weekly inventories reports) or changes in market expectations of oil inventories. These oil-related events are described in Kilian (2009) as "precautionary demand shocks," as they are likely to be associated with concerns about the availability of future oil supplies.

We choose not to include in any of our three definitions events such as OPEC or non-OPEC oil exporters' changes of their production plans or such proposals (event-types 13 and 14). In fact, these events are likely to reflect oil producer's endogenous responses to developments in global oil markets or in other sectors of the world economy. For a similar reason, we choose not to include in any of our definitions changes in oil demand, such as the global economic growth, and improvements in oil usage efficiency (event-types 18 and 19). However,

\footnotetext{
${ }^{6} \mathrm{We}$ are grateful to Christina Romer and David Romer for making this suggestion.

${ }^{7}$ Interestingly, we also find that political developments and military tensions in non-oil-producing countries (event-types 9 and 12) were not mentioned even once in oil-market analyses during the past 25 years. This indicates that such events had essentially no effect on global oil supply and demand.
} 
as these events represent a very important portion of the developments that have occurred in the global oil market, in the following sections we will examine their macroeconomic effects separately. ${ }^{8}$

\section{Constructing Monthly Oil Shock Series}

The ultimate goal of our work is to examine the effects of various kinds of oil shocks on the U.S. economy. As the highest available frequency for most macroeconomic data is monthly, to facilitate the econometric analysis, we aggregate our daily oil shock series into monthly series. Specifically, for each trading day, we attribute the daily shocks to an event type based on the code assigned to that particular day. ${ }^{9}$ We then aggregate the 22 daily shock series into the same number of monthly series. ${ }^{10}$ Finally, for each of our definitions of exogenous oil-related events, as well as for any other combination of oil-related events that is of potential interest, we construct a monthly oil-price shock measure to be used in our econometric analysis later.

Figures 1A and 1B display our market information-based measures of oil-price shocks, with the shocks defined as the "predicting error" from equation (1) and as the "log-price change," respectively. To improve the readability of the time plot of shock series, in these figures we display the annual average of monthly series (the original monthly series are shown in Figures 2A and $2 \mathrm{~B}$ ). The three market-information-based measures are quite similar. Consider, for example, the shock measures constructed as the "predicting error" : The correlation between the "baseline" measure and the "broad" measure is 78 percent, between the "baseline" and the "narrow" measures is 72 percent, and between the "narrow" and the "broad" measures is 55 percent. In addition, shock series constructed following the two quantitative approaches (i.e., the "predicting error" and the "log-price change") are also very similar: The correlation between the "baseline" measures constructed in these two different ways is 90 percent, and the corresponding correlations are 87 percent for the "broad" measures and 88 percent for the "narrow" measures.

Figure 1C displays two VAR-based measures that are widely used in the literature. The first one is based on the "net oil price increase" (NOPI) indicator of the oil market proposed by

\footnotetext{
${ }^{8}$ To facilitate possible future work by other researchers, in constructing our database we have preserved as much primitive information as possible about oil-market developments. Interested readers can select the definitions of exogenous oil-related events of their own choice and construct the corresponding alternative measures. ${ }^{9}$ If multiple codes are assigned to the day, the shocks will be equally divided among corresponding event types.

${ }^{10}$ Here we assume that temporal aggregation of daily shock series into corresponding monthly series has no effect on our estimates of impulse response coefficients, which may require additional assumptions (Marcellino 1999). We thank an anonymous referee for pointing it out to us.
} 
Hamilton (1996), and the second one is based on the log change in the producer price index (PPI) for crude oil, as, for example, in Bernanke, Gertler, and Watson (1997) and Blanchard and Galí (2009). Both these VAR-based measures are the estimated residuals from a recursive VAR that includes macroeconomic variables and an indicator of oil prices, with the oil-price indicator ordered as the last variable in the VAR system. The only difference between the two is whether it is the NOPI or the log change in the PPI for crude oil that enters the VAR. In the later analysis, we refer to them as the "asymmetric" VAR-based measure and "symmetric" VAR-based measure, respectively, and explain their construction in detail in Section III.

Figures 2A and 2B compare our market information-based measures with these two traditional VAR-based measures on a monthly frequency. As shown in the figures, there are substantial similarities and, at the same time, significant differences between the traditional VARbased measures and our market information-based measures. Both kinds of oil-price shock measures capture major oil-price spikes reasonably well, for instance, during the periods March-April 1986, August-September 1990, December-February 1991, April 1999, and September-October 2004. However, the magnitudes of the shocks are somewhat different. In fact, the symmetric VAR-based measure is the most volatile series of the three, and the asymmetric VAR-based measure is the least volatile. The correlation between our "baseline" oil-shock measure ("predicting error") and the asymmetric VAR-based measure is 24 percent, while the correlation between the "baseline" and the symmetric VAR-based measures is 23 percent. Correlation between the two VAR-based measures is 53 percent.

Such differences are not surprising. First, the two VAR-based measures are residuals from vector autoregressions that include macroeconomic variables, whereas the market informationbased measures are either residuals from an oil-price forecasting equation that does not incorporate macroeconomic variables or simply log changes of the oil price. Second, and more important, the approaches adopted to recover the oil-price shocks are completely different. We adopt an "event-study" approach and rely on market information to identify exogenous oil-price shocks, whereas the traditional VAR-based measures rely on the recursive ordering of the corresponding variables. For example, if the price of oil rises sharply following an expansion in the level of global economic activity, the traditional VAR approaches may interpret the increase in the oil price as a shock. Our methodology, in contrast, correctly classifies it as an increase in oil demand related to the global business cycle (event-type 18 or 19), and will, correspondingly, exclude it from our exogenous oil-price shock measures. 


\section{Estimating the Effects of Oil-Price Shocks}

In this section we examine the dynamic effects of oil-price shocks on the U.S. economy. For this purpose, we estimate a vector autoregressive model with a conditioning exogenous variable corresponding to our measure of oil-price shock. ${ }^{11}$ In the econometrics literature, this type of model is sometimes referred to as a VARX model or as a rational distributed lag model (see Lütkepohl, 2005, chapter 10). Thus, our estimating system of equations is:

$$
X_{t}=A_{0}+A_{1} t+A_{2}(L) X_{t-1}+B(L) O_{t}+\varepsilon_{t},
$$

where $X_{t}$ is a vector that contains the log of real GDP, the log of the consumer price index (CPI), the level of the federal funds rate, and the log of the real price of oil, defined as the difference between the log of the producer price index (PPI) for crude oil and the log of the CPI. ${ }^{12}$ The variable $O_{t}$ is an oil-price shock measure, and it represents the observable exogenous input variable, which is determined outside of the system in equation (2). $A_{0}$ and $A_{1}$ are vectors of coefficients, while $A_{2}(L)$ and $B(L)$ are two finite-order polynomials in the lag operator $L$. Finally, $t$ is a time trend, and $\varepsilon_{t}$ a vector of white noise and mean-zero i.i.d. error terms. The estimated dynamic responses of the endogenous variables in $X_{t}$ to an oil-price shock $k$ periods ahead are given by the point estimate of the coefficients on $L^{k}$ in the expansion of the rational transfer function, $\left[I-A_{2}(L) L\right]^{-1} B(L)$. A similar strategy is also adopted by Christiano, Eichenbaum, and Evans (1999) and Burnside, Eichenbaum, and Fisher (2004) in estimating the effects of monetary and fiscal policy shocks, respectively.

In particular, to estimate the effects of oil-price shocks, we substitute the market informationbased shock measures from Section II for $O_{t}$, one at a time, and estimate the impulse response functions. ${ }^{13}$ Of course, the consistency of the VARX estimates depends on the exogeneity of the constructed oil-shock series $O_{t}$. As these shock series are derived independently of our estimating system and are based on market information, by construction they should be exogenous. To further confirm their validity, we perform a number of statistical

\footnotetext{
${ }^{11}$ The set of exogenous variables also includes a deterministic time trend.

${ }^{12}$ Our choice of the endogenous variables included in the vector $X_{t}$ is very similar to that in Bernanke, Gertler, and Watson (1997), except that their VAR also includes a commodity price index to capture the effect of monetary policy shocks. As the primary focus of our study is oil-price shocks, we choose not to include the commodity price index in the vector of endogenous variables, $X_{t}$, similarly to Blanchard and Galí (2009).

${ }^{13}$ There are six alternative oil-price shock series constructed using our methodology_-"baseline," "broad," or "narrow" definition of exogeneity, and for each definition shock magnitudes are calculated using either "logprice change" or "predicting error" methods. For exposition purpose below we will focus on the oil-price shock series constructed according to the "baseline" definition of exogeneity. Estimation results based on "broad" and "narrow" definitions will be discussed in Section IV.D when we conduct "Robustness and Stability" checks.
} 
tests on the exogeneity of our shock measures with respect to the endogenous variables in the VARX model.

First, we run a battery of Granger-causality tests. Specifically, we test whether the coefficients of the lagged values of the four endogenous variables in the VARX system, namely, real GDP, the CPI, the federal funds rate, and the PPI for crude petroleum, are zero in an estimation equation for $O_{t}$. The test statistics, as displayed in Table 2, suggest that the null hypothesis that all coefficients are zero cannot be rejected. This finding is valid both when the test is conducted individually on each endogenous variable and when the test is conducted jointly on all four endogenous variables at the same time. For instance, when we consider our "baseline, log-price change" definition of oil-price shocks as the dependent variable, the $p$-value for the null hypothesis that all 24 coefficients ( 4 variables, 6 lags for each) are zero in a joint test is 36 percent. This indicates that the lagged values of the endogenous variables in the VARX system (2) do not help predict our constructed shock series $O_{t}$. Next we conduct a "strong exogeneity" test as suggested by Bierens (2004), which is to jointly test whether the residual terms $\varepsilon_{t}$ in the equations for $X_{t}$ are uncorrelated to the residual terms in the equation for $O_{t}$, in addition to the zero coefficient restrictions as in Granger causality test. Again, the Likelihood Ratio test statistics $\left(\chi^{2}(28)\right.$ - 24 zero-coefficient restrictions plus 4 zero-covariance restrictions) suggest that the null hypothesis of zero coefficients and uncorrelated residual terms cannot be rejected. Thus both Granger causality test and strong exogeneity test confirm the validity of our market information-based measures of oil shocks and suggest the consistency of the VARX model estimates.

We estimate the model in equation (2) using six lags. The sample consists of monthly data, with the sample period running from January 1984 to October 2007. Since the highest frequency available for real GDP is quarterly, following the work of Bernanke, Gertler, and Watson (1997), we adopt the method of Chow and Lin (1971) to obtain a monthly indicator for real GDP. ${ }^{14}$ In an earlier version of our work, we have also estimated a univariate distributed lag model, the same kind of strategy adopted by Ramey and Shapiro (1998) and Kilian (2009), and the estimated effects obtained there are very similar to those implied by the VARX model in equation (2).

Finally, as mentioned earlier in Section II, for comparison we also estimate the impulse responses implied by two widely used VAR-based oil-price shock measures. The first measure is the asymmetric VAR-based measure, which is constructed using the "net oil-price increase" (NOPI) indicator proposed by Hamilton (1996). The NOPI is defined as the maximum be-

\footnotetext{
${ }^{14}$ As interpolators, we use the monthly series for industrial production and total capacity utilization.
} 
tween zero and the difference between the log of the current oil price and the maximum value of the log of the oil price during the preceding year. ${ }^{15}$ The asymmetric VAR-based measure is thus the estimated residuals from the last equation in a recursive four-variable VAR that includes, in the following order, the log of real GDP, the log of the CPI, the level of the federal funds rate, and the NOPI. The second VAR-based measure, the symmetric one, is constructed in a similar way, except that it is the change in log oil price, rather than the NOPI, that enters as the last-ordered variable. Bernanke, Gertler, and Watson (1997) and Blanchard and Galí (2009) build their VAR systems in a very similar fashion.

\section{EMPIRICAL RESULTS}

\section{A. Impulse Responses of Market-Information-Based Exogenous Oil-Price Shocks}

Figure 3 displays the estimated impulse responses for real GDP, the CPI, the federal funds rate, and the real price of oil, as implied by our baseline measure of oil-price shocks, with shock magnitudes computed using both the "log-price change" and the "predicting error" methods. As the impulse responses of the real price of oil will generally be different when different shock measures are substituted into the system of equations (2), to facilitate the comparison of their macroeconomic effects, we normalize these oil-shock measures so that the peak response of the real price of oil is 10 percent. ${ }^{16}$ The magnitude of this normalization is roughly equivalent to 1.75 times the estimated standard deviations of the market informationbased shock measures. Statistical inference on the point estimates of the impulse response coefficients is obtained through a standard residual-based bootstrap method with 1,000 replications, and the resulting 95 percent standard percentile confidence intervals are denoted by the shaded areas in the figures.

The estimated impulse responses fit quite well with the conventional-wisdom view, that following a positive oil-price shock, real GDP declines and the overall price level increases. For instance, in the left panel of Figure 3 where shock sizes are calculated using "log-price

\footnotetext{
${ }^{15}$ This indicator detects increases that establish new highs relative to most recent readings and that do not reverse previous decreases. In a recent study, however, Kilian and Vigfusson (2011) challenge the use of asymmetric VAR models on the basis of little evidence against the symmetry hypothesis in response to oil-price shocks. ${ }^{16}$ Blanchard and Gali (2009) normalize the size of the shock so that it induces an increase in the oil price by 10 percent on impact. As can be seen in Figure 3 and in the following figures, our estimation implies that the responses of the real price of oil are usually hump-shaped, with the peak response occurring in the first or second month after the shock. Therefore, we choose to normalize the size of the shocks according to their largest responses rather than their impact responses. In most cases, the normalized shock sizes are very similar.
} 
change" method, in response to the shock, real GDP gradually declines, with the largest response (in absolute value, same below) arriving about 18 months after the shock. The response becomes statistically significant three months after the shock, and remains significant throughout the 24-month horizon. These point estimates imply a substantial impact of exogenous oil-price shocks on the real economy. Over the 24 months following the shock, the implied cumulative output loss is equivalent to 6.8 percent of a month's real GDP, or about 0.6 percent of annual real GDP in two years. The CPI shifts up immediately on impact, and the peak response arrives three months after the shock. Price increase is both substantial and persistent, on average 14 basis points higher during the 24-month horizon following the shock, and the CPI remains 10 basis points higher than its pre-shock level even 24 months after the shock.

In response to the initial rise in the CPI, the federal funds rate rises by a few basis points in the first three months after the shock. However, with real GDP continuing to decline and inflation gradually decelerating, monetary policy becomes more accommodative. The 24-month cumulative decline in the federal funds rate reaches 2.6 percentage points, or about 11 basis points lower than its pre-shock level each month on average. The response of the real oil price to the shock is hump-shaped, with the peak arriving one month after the shock, and oil price increase remains statistically significant even eight months after the shock. Estimates of the impulse responses when shock sizes are calculated in "log-price change" are fairly similar (Figure 3, right column), with the responses remaining statistically significant and persistent. Impulse responses to the "broad" and "narrow" measures of exogenous oil-price shocks are also similar and will be discussed later in Section IV.D when we check the robustness of our findings.

\section{B. Impulse Responses of VAR-Based Measures of Oil-Price Shocks}

The estimated impulse responses displayed in Figure 3 are substantially larger and more significant than earlier estimates of the effects of oil-price shocks in the literature, in particular with regard to the output responses. For example, Bernanke, Gertler, and Watson (1997) estimate the macroeconomic effects of oil-price shocks in a VAR setting, using four alternative indicators of oil-price shocks. ${ }^{17}$ Estimating their VAR over the period 1965-1995, they find that none of their specifications generate a statistically significant output response to an

\footnotetext{
${ }^{17}$ The indicators they have used include: (1) changes in the log of the nominal PPI for crude oil, (2) the HooverPerez dummies for political and military events in the Middle East, scaled by the log change of the nominal PPI for crude oil, (3) the indicator proposed by Mork (1989), i.e., positive monthly changes in the log of the real price of oil, and (4) Hamilton's NOPI measure.
} 
oil-price shock. Moreover, with the federal funds rate increasing persistently in response to a higher price level after the shock, they argue that it is hard to determine how much of the output decline is the direct result of the oil shock, rather than the indirect result of the tighter monetary policy. This is an evident example of the identification issue that VAR models usually face. Therefore, they conclude "finding a measure of oil price shocks that 'works' in a VAR context is not straightforward."

Hooker (1996) employs a similar VAR approach and examines two specifications, with the oil-price indicator defined as the log change in the nominal oil price and the log level of the real oil price, respectively. Interestingly, he finds that oil prices did not Granger-cause U.S. GDP or unemployment from 1973 to 1994. Rather, GDP growth exhibited a large positive response to an oil price increase for about four quarters and then quickly returned to its preshock level, contradicting the conventional-wisdom view on the macroeconomic effects of oil-price shocks. Bernanke, Gertler, and Watson (1997) report a similar output response when using the log change in the nominal oil price as an indicator of the state of the oil market. However, by using his "net oil-price increase" (NOPI) measure in a univariate autoregressive model, Hamilton (1996) finds a negative output response to an oil-price shock after 1973, although the estimated response is substantially weaker than his pre-1973 estimate and, at the same time, also statistically insignificant.

To illustrate the differences between the estimated macroeconomic effects implied by our market information-based measures and those implied by the traditional measures, we construct two VAR-based measures of shocks, the asymmetric and symmetric measures as defined in Section III, and estimate the same VARX system as in (2). We substitute these two VAR-based measures for the exogenous input variable $O_{t}$, one at a time, and estimate the impulse responses to the constructed oil-price shocks. ${ }^{18}$

The left column in Figure 4 displays the impulse responses to the asymmetric VAR-based shock measure, constructed in the same way as Hamilton (1996). Following the shock, real GDP declines and the CPI rises. However, the output response is no longer statistically significant and is also substantially weaker than the response implied by our market informationbased measures. For instance, the 24-month cumulative output loss implied by the asymmetric VAR-based measure is only 1.7 percent, only a quarter of the 6.8 percent output loss implied by our "baseline" measure shown in Figure 3. The responses of the CPI and the federal funds rate are also substantially weaker and become statistically insignificant.

\footnotetext{
${ }^{18}$ As above, the shock sizes are normalized so that the peak response of the oil price is 10 percent.
} 
The output response to an oil-price shock implied by the symmetric VAR-based measure (i.e., with the log of the real price of oil entering as the last ordered variable in the VAR), shown in the right column of Figure 4, is slightly stronger than the response implied by the asymmetric VAR-based measure. In particular, the cumulative output loss in the 24 months after the shock is 2.9 percent, although still less than half of the 6.8 percent cumulative output loss implied by our baseline oil-shock measure. More importantly, the response of real GDP remains statistically insignificant during most of the 24-month period following the shock. These estimates confirm the findings of earlier studies in the literature, that VAR-based identification strategies usually yield a weak and statistically insignificant output response.

It is also worth noting that the point estimates and the statistical significance of the output response as implied by the symmetric VAR-based measure (right column of Figure 4) are also quite close to those in the most recent study by Blanchard and Galí (2009), who have estimated a similar VAR using the log of the oil price as an indicator of the state of the oil market. In particular, in their second subsample period (1984:Q1 to 2005:Q4), the cumulative real GDP loss is about 1.6 percent of quarterly GDP over three years (see their Figure $6 a)$, or about 0.13 percent of annual GDP each year on average. These estimated cumulative output losses are quantitatively very close to the above estimate of a cumulative loss of 2.9 percent of monthly GDP in two years as implied by the symmetric VAR-based shock measure, i.e., 0.12 percent of annual GDP loss each year on average. This is not surprising. In fact, our sample period (1984:M1 to 2007:M10) overlaps with theirs considerably, the VARs are constructed in a similar fashion, and the shock size is normalized by a similar magnitude. Blanchard and Galí have also found that in the 1960s and 1970s, the response of U.S. GDP is substantially larger and statistically significant. Because of this finding, they conclude that oil-price shocks have had a much smaller effect on the U.S. economy since 1984. Our estimation results paint a different scenario: even during the past two decades, exogenous oil-price shocks have continued to exert substantial and significant effects on the U.S. economy, as the output losses implied by our market information-based measure are substantially larger than those of Blanchard and Galí (2009).

We illustrate this point more clearly in Figure 5, where we compare the impulse responses implied by the two VAR-based measures with those implied by our baseline shock measure, along with the corresponding 95 percent confidence intervals of the latter. As it appears from the figure, the real GDP response implied by the market information-based measure is significantly larger than the ones implied by the traditional VAR-based shock measures. In fact, the point estimates of the latter lie outside the 95 percent confidence intervals of the former for several months, in particular the output response implied by the asymmetric VAR-based mea- 
sure. The responses of the CPI are more similar, which is not surprising, as increases in oil prices directly affect the non-core (food and energy) component of the CPI by construction of the index.

Why are the output responses implied by the VAR-based measures so different from the responses implied by the market information-based measures? One possible explanation is that the VAR identification strategy fails to separate oil-price fluctuations driven by exogenous shocks from endogenous fluctuations driven by other kinds of structural shocks. For instance, a productivity shock may lead to an economic expansion and, through a demand channel, to higher oil prices. Consequently, it will generate a positive correlation between real GDP growth and oil-price movements. Therefore, although a "pure" positive exogenous oil-price shock would lead to a substantial output decline, the VAR identification strategy may fail to separate these two kinds of shocks, thereby inducing a substantially weaker and statistically insignificant estimate of output response.

Our narrative approach provides an opportunity to directly examine this conjecture. In particular, if the above explanation is correct, then we should expect a much less negative, or possibly, even a positive, output response following an oil-price increase that is induced by gains in productivity or other kinds of endogenous oil-price increases responding to changes in oil demand. For this purpose, we construct an alternative series of oil-price shocks. We combine the shock series corresponding to event-types 18 and 19 (that is, events related to changes in oil demand due to the business cycle, improvement in oil usage efficiency, technology, etc.) and include the resulting shock variable as the input variable $O_{t}$ in the system of equations (2). We plot the implied impulse responses in Figure 6, with the shock sizes calculated using both the "log-price change" and the "predicting error" approaches.

In both columns of the figure, the estimated impulse responses indicate that the narrative approach has correctly identified this kind of shock. Specifically, after a demand-driven shock, real GDP increases and the CPI level declines despite the fact that the non-core component of the CPI rises. The federal funds rate barely moves, as a potential increase driven by the higher output is partly offset by a decrease driven by the decline in the general price level. These are exactly the qualitative responses that one would expect following a positive productivity shock. These results also confirm Kilian's (2009) finding that an expansion in global aggregate demand leads to an increase in U.S. real GDP growth and, at the same time, in the price of oil. ${ }^{19}$

\footnotetext{
${ }^{19}$ As in Kilian (2009), the output response we obtain here is statistically insignificant, possibly reflecting the small number of observations corresponding to such shocks in our sample period.
} 
What distinguishes our findings from those of Kilian (2009) is that he has identified a global aggregate-demand shock, which drives up the CPI in the U.S., whereas our narrative reading has detected changes in oil demand likely reflecting productivity gains, which drives down the CPI in the U.S. Looking more closely at the timing of such events also confirms this point. In fact, in our sample, such shocks occurred primarily after 2000, consistent with what many have suggested, that the oil-price increases occurred over the 2002-2008 period were the result of "an expanding world economy driven by gains in productivity" (The Wall Street Journal, August 11, 2006), which, among other things, were reflected in rapidly rising imports into the U.S. of inexpensive consumer goods from China and other emerging market economies and the associated deflationary pressures in the U.S. ${ }^{20}$ Over time, real GDP declines, as the adverse effect of higher oil price eventually dominates the initial stimulating effect of the productivity shock. However, the CPI remains below its pre-shock level, as the price decline originating from the initial productivity shock still overweighs the inflationary pressures arising from higher oil prices even 18 months after the shock.

\section{Other Kinds of Oil-Price Shocks Based on Market Information}

Next we examine the macroeconomic effects of other kinds of oil-price "shocks" identified through our narrative approach. These shocks reflect an important portion of the fluctuations observed in the global oil market during the past two and a half decades. Traditional VAR identification strategies are normally unable to separate these kinds of "shocks" from exogenous oil shocks.

\section{OPEC and Non-OPEC Oil-Price Shocks}

OPEC and non-OPEC oil exporters' decisions to change their production plans may represent another source of endogenous oil-price fluctuations. We include these events in our eventtypes 13 and 14 (see Table 1). One could reasonably argue that these decisions may reflect endogenous responses of oil producers to developments in the global oil market and, more generally, in the global economy (Barsky and Kilian $(2002,2004)) .^{21}$ As we have done with other event types, here we also construct a corresponding "shock" series and examine its effects on the U.S. economy.

\footnotetext{
${ }^{20}$ Two recent studies, Hamilton (2009b) and Kilian and Hicks (2009), also attribute the oil-price hikes during 2003-2008 to stronger demand led by an expansion in the world economy, in particular in China and India.

${ }^{21}$ Nakov and Pescatori (2010) develop a model in which the global supply of oil is determined by the optimal production decisions of a dominant supplier and a fringe of competitive producers, representing, respectively, OPEC and non-OPEC oil exporters. One implication of their framework is that the price of oil is ultimately a function of OPEC's share in the global oil market.
} 
As displayed in Figure 7, in response to this kind of "shock," real GDP declines and the CPI rises. The price of oil increases, with the peak response arriving three months after the "shock," and the federal funds rate rises significantly in response to the substantial CPI increase amid only modest output decline. This pattern is different from what is induced by a typical productivity shock (Figure 6), or an exogenous oil-price shock (Figures 3). In particular, the output loss implied by an OPEC/non-OPEC oil exporters' shock is substantially weaker than the output loss induced by an exogenous oil-price shock, with the output response remaining statistically insignificant; ${ }^{22}$ however, output does not rise either as much as in Figure 6 when responding to a positive global aggregate demand shock. Accordingly, the monetary policy authority's response also lies between its responses in those two cases, as it becomes restrictive rather than accommodative, as in Figures 3 when responding to exogenous oil shocks, but not as restrictive as in Figure 6 when responding to a demand-driven oil shock. This result is consistent with the finding in the literature that oil prices no longer Granger-cause real GDP and other macroeconomic variables after 1973, when OPEC became able to affect effectively the global oil market (see Hooker, 1996).

\section{Oil Market-Specific Demand Shocks}

Event-types 15 through 17 reflect demand shocks that are specific to the oil market, i.e., changes in oil demand unrelated to changes in the level of global economic activity. For example, changes in the U.S. Strategic Petroleum Reserve (SPR) in the past two decades have always been associated with substantial oil price changes. ${ }^{23}$ Changes in commercial oil and gas inventories, including both realized changes and market expectations of future changes, have also significantly affected the oil market. These oil market-specific demand changes often reflect changes in the precautionary demand for oil, as discussed in Kilian (2009).

An oil market-specific demand shock drives up the real price of oil, by definition. The price increase, however, is not as persistent as the one induced by the exogenous oil-price shocks, as the real price of oil returns to its pre-shock level in about five months (Figure 8), suggesting that such temporary supply-demand imbalance in oil market are often accommodated by oil producers' supply adjustments within a few months.

\footnotetext{
${ }^{22}$ Note that "OPEC announcements" is the most frequent event type in our sample, with a frequency of 742 trading days. Therefore, the lack of statistical significance is unlikely due to a lack of observations.

${ }^{23}$ For example, on January 23, 2007, the U.S. Department of Energy announced that the U.S. would double the size of its Strategic Petroleum Reserves (SPR) over the next two decades. The crude oil price responded with a 7.6 percent rally on the same day. On September 13, 2000, after the White House mentioned that it was considering a release of SPR in response to oil price increases, the price of oil dipped 1.5 percent. It dropped another 3 percent three weeks later, on October 5, 2000, the day the SPR release was officially confirmed.
} 
In response to the shock, real GDP declines, although the decline is less persistent and quantitatively much weaker than the decline implied by an exogenous oil shock: real GDP returns to its pre-shock level in about six months, and the 24-month cumulative output loss is 2.2 percent of monthly GDP, compared with a 6.8 percent cumulative output loss implied by exogenous oil shocks. Moreover, the decline in output is statistically significant at the 95 percent level only for the first three months after the shock. The CPI increases immediately after the shock, but then returns to its pre-shock level in four months. Because of the short-lived output and CPI responses, monetary policy accommodation is quite limited. The impulse responses induced by the oil market-specific demand shocks identified by our narrative approach are less persistent than those induced by the precautionary demand shocks identified by Kilian (2009). One possible explanation for this difference is that, in his work, the precautionary demand shocks are identified as any real oil-price movement that cannot be explained by his measures of changes in global real economic activities or oil production, and thus may include some of the event types that are included in our exogenous shock measures, such as political development or military actions.

\section{Oil-Price Shocks Related to Military Actions in The Middle East}

Finally, we examine the effects of oil-price shocks related to military actions in the Middle East. Not surprisingly, these actions tend to drive up the real price of oil and lead to a substantial output decline (Figure 9). In particular, real GDP gradually decreases, with the largest decline arriving 11 months after the shock. The decline is statistically significant at the 95 percent level for most horizons, and the cumulative output loss over 24 months reaches 8.4 percent of monthly GDP, even larger than the 6.8 percent output loss implied by our baseline exogenous shock measure. Moreover, if one argues that U.S. military spending tends to increase in response to these military actions and that such increases will stimulate the U.S. GDP, then the actual GDP decline induced by these military shocks through the oil-price channel could be even larger than the decline implied by our estimates. Therefore, our estimates indicate a strongly adverse effect on the U.S. economy of oil-price shocks induced by military conflicts in the Middle East, events that tend to raise the market's concerns over oil supply disruptions as well as future oil availability. The CPI also increases after the shock, although the increase is smaller and less significant than when responding to exogenous oil shocks. Monetary policy becomes even more accommodative than in the baseline exogenous oil shock case, with the federal funds rate decreasing by a cumulative 5.2 percentage points over 24 months after the shock, or 22 basis points lower than the pre-shock level on average, significantly larger than the 14-basis point decline when responding to an exogenous oil-price shock. 


\section{Robustness and Stability}

We perform a number of robustness and stability checks to verify the validity of our main conclusions. First, we estimate the implied impulse responses using two alternative definitions of "exogeneity" as defined in Section II.C, specifically, the "narrow" definition of exogenous oil events consisting of event types 1 through 9 in the list of Table 1, and the "broad" definition consisting of event types 1 through 12, as well as types 15 through 17 of the list. The implied impulse responses, as shown in Figures 11 and 12 of the appendix, are very similar to those obtained using the "baseline" definition of exogeneity. In particular, the output responses to oil-price shocks are still statistically significant, and the 24-month cumulative output loss under the "broad" definition measure is even stronger than those implied by the "baseline" definition, reaching 8.4 percent, or 0.7 percent of a year's real GDP in two years following the shock. In an earlier version of this paper, we have also obtained results for alternative measures of price level (e.g., the personal consumption expenditure deflator), as well as for a univariate, distributed lag model specification. None of those variants generate significantly different results from the above conclusions and are thus omitted here.

We have also checked the stability of the estimated impulse responses across different periods. We consider two subsample periods_-January 1984 to December 1994 and January 1995 to October 2007-and estimate the impulse responses for these two periods as implied by various shock measures separately. Table 3 summarizes the estimation results of this stability check. As above, to facilitate the comparison of the effects of different oil-price shock measures, the shock sizes are normalized so that the largest response of the real price of oil is 10 percent. Under the heading "output," we report the 24-month cumulative output loss, which is equal to the sum of impulse response coefficients for output. Under the heading "price," we report the sum of impulse response coefficients over 24 months for the CPI, divided by 24 , which can be interpreted as the average increment in the CPI over the two years after the shock. Finally, under the heading "interest rate," we report the sum of impulse response coefficients for the federal funds rate, divided by 24 , which measures the average monetary policy response during the two years after the shock.

When the 24-year sample period is split into two subsample periods (1984-1994, 1995-2007), the responses implied by the two VAR-based measures differ greatly across the two subsample periods, with the directions of the real GDP and CPI responses bearing exactly the opposite signs. For instance, for the pre-1995 subsample period, the estimates implied by the asymmetric VAR-based measure indicate that following an oil-price shock, real GDP declines, with the 24-month cumulative output loss reaching 4.2 percent. In stark contrast, 
for the subsample period after 1995, the corresponding estimates indicate that real GDP increases, with a cumulative output gain of 3.6 percent in the 24 months after the shock (Figure 10). Likelihood ratio test also suggests that the $p$-value for a null of identical impulse responses across these two subsample periods can be rejected at the 5\% significance level. With regard to the symmetric VAR-based measure, in the first subsample period, real GDP barely declines after the shock, with the 24-month cumulative output gaining 0.5 percent, consistent with the earlier literature's findings that the symmetric oil-price measure cannot generate a positive output response following the oil-price declines in the mid-1980s (Hamilton, 1996). The estimates from the second subsample, however, are more consistent with the conventional wisdom: real GDP declines after the oil-price shock, with a cumulative output loss of 2.7 percent over the 24 months after the shock. However, estimates using the market information-based measures suggest that the output response has not changed substantially across these two subsample periods, with real GDP declining significantly after the exogenous oil-price shocks by a similar amount in both periods, and the $p$-value for a null of identical impulse responses across the two subsample periods is $32 \%$, i.e., the null cannot be rejected at any commonly used significance level. The positive output response implied by the asymmetric VAR-based measure for the post-1995 subsample may simply reflect a predominance of demand-driven oil-price shocks since the late 1990s, likely originating from a global economic expansion (Kilian 2009), rather than genuine exogenous oil-price shocks.

\section{Concluding Remarks}

This paper combines narrative and quantitative approaches to examine the dynamic effects of oil-price shocks on the U.S. economy. To correctly identify exogenous oil shocks, we first collect oil-market related information from a number of oil-industry trade journals, and compile a database identifying all the events that have affected the global oil market on a daily basis since 1984. Based on such information, we are able to isolate events that are exogenous to the U.S. economy and construct corresponding measures of exogenous oil-price shocks. Furthermore, shock magnitudes are calculated by running a real-time oil-price forecasting model incorporating oil futures prices. These procedures help alleviate the endogeneity and predictability problems that have pestered the traditional VAR identification strategies in the literature.

One contribution of our work is the thorough examination of all kinds of oil-related events in the past two and a half decades, more comprehensive than just focusing on geopolitical or military events, as most of the earlier literature has done so far. Moreover, in constructing the 
database, we have preserved as much primitive information on the oil-market developments as possible, with the hope of facilitating possible future studies by other researchers on the nature and implications of these events.

After deriving our measures of various kinds of oil shocks, we go on to examine their dynamic macroeconomic effects. We find that exogenous oil-price shocks have had substantial and statistically significant effects on the U.S. economy during the past two and a half decades. In contrast, traditional VAR identification strategies imply a substantially weaker and insignificant real effect for the same period. Further analysis reveals that this discrepancy is likely to stem from the inability of VAR-based approaches to separate exogenous oil-supply shocks from endogenous oil-price fluctuations driven by changes in oil demand. Notably, our study also suggests that the U.S. economy may not have become as insulated from oil shocks during the last two and a half decades as earlier studies have suggested. To examine fully how the oil price-macroeconomy relationship has evolved during the whole postwar period, a thorough study along the same narrative and quantitative approach for the period prior to the "Great Moderation" is called for. This will be the topic for future research. 


\section{REFERENCES}

Alexopoulos, Michelle, 2011, "Read All About It! What Happens Following a Technology Shock," American Economic Review 101, 1144-79.

Alexopoulos, Michelle, and Jon Cohen, 2009, "Measuring Our Ignorance, One Book at a Time: New Indicators of Technological Change, 1909-1949," Journal of Monetary Economics 56, 450-470.

Alquist, Ron and Lutz Kilian, 2010, "What Do We Learn from the Price of Crude Oil Futures?” Journal of Applied Econometrics 25, 539-573.

Barsky, Robert B., and Lutz Kilian, 2002, "Do We Really Know that Oil Caused the Great Stagflation? A Monetary Alternative.” In: Bernanke, Ben S. and Kenneth Rogoff (Eds.), NBER Macroeconomics Annual 2001. MIT Press, Cambridge, 137-183.

Barsky, Robert B., and Lutz Kilian, 2004, "Oil and the Macroeconomy since the 1970s," Journal of Economic Perspectives 18, 115-134.

Bernanke, Ben S., Mark Gertler, and Mark Watson, 1997, "Systematic Monetary Policy and the Effects of Oil Price Shocks.” Brookings Papers on Economic Activity, 1997:1, 91-157.

Bierens, Herman J., 2004, "VAR Models with Exogenous Variables.” Pennsylvania State University.

Blanchard, Olivier J. and Jordi Galí, 2009, “The Macroeconomic Effects of Oil Shocks: Why are the 2000s so Different from the 1970s?” In: Galí, Jordi and Mark Gertler (Eds.), International Dimensions of Monetary Policy. University of Chicago Press: Chicago, 373-421.

Burnside, Craig, Martin Eichenbaum, and Jonas D.M. Fisher, 2004, "Fiscal Shocks and Their Consequences," Journal of Economic Theory 115, 89-117.

Chinn, Menzie D., and Olivier Coibon, 2010, "The Predictive Content of Commodity Futures," working paper, College of William and Mary and University of Wisconsin.

Chinn, Menzie D., Michael LeBlanc, and Olivier Coibon, 2005, “The Predictive Content of Energy Futures: An Update on Petroleum, Natural Gas, Heating Oil and Gasoline," NBER Working Paper No. 11033.

Chow, Gregory C., and An-loh Lin, 1971, "Best Linear Unbiased Interpolation, Distribution and Extrapolation of Time Series by Related Series," Review of Economics and Statistics 53, 372-375.

Christiano, Larry J., Martin Eichenbaum, and Charles L. Evans, 1999, “Monetary Policy Shocks: What Have We Learned and to What End?" In: Taylor, John B. and Michael Woodford (Eds.), Handbook of Macroeconomics, Vol. 1A, North-Holland, Amsterdam, 65-148.

Cochrane, John H. and Monika Piazzesi, 2002, “The Fed and Interest Rates: A Highfrequency Identification,” American Economic Review 92, 90-95. 
Cochrane, John H. and Monika Piazzesi, 2005, "Bond Risk Premia," American Economic Review 95, 138-160.

Hamilton, James D., 1983, “Oil and the Macroeconomy Since World War II," Journal of Political Economy 91, 228-248.

Hamilton, James D., 1985, "Historical Causes of Postwar Oil Shocks and Recessions," Energy Journal 6, 97-116.

Hamilton, James D., 1996, "This is What Happened to the Oil Price-Macroeconomy Relationship," Journal of Monetary Economics 38, 215-220.

Hamilton, James D., 2003, “What is an Oil Shock?” Journal of Econometrics 113, 363-398.

Hamilton, James D., 2009, “Understanding Crude Oil Prices,” Energy Journal 30, 179-206.

Hamilton, James D., 2009, “Causes and Consequences of the Oil Shock of 2007-08," Brookings Papers on Economic Activity, Spring 2009, 215-259.

Hooker, Mark A., 1996, "What Happened to the Oil Price-Macroeconomy Relationship?" Journal of Monetary Economics 38, 195-213.

Hoover, Kevin D. and Stephen J. Perez, 1994, "Post Hoc Ergo Propter Hoc Once More: An Evaluation of 'Does Monetary Policy Matter?' in the Spirit of James Tobin," Journal of Monetary Economics 34, 89-99.

Kassarjian, Harold H., 1977, “Content Analysis in Consumer Research,” Journal of Consumer Research 4, 8-18.

Kilian, Lutz, 2008, "Exogenous Oil Supply Shocks: How Big Are They and How Much do They Matter for the U.S. Economy?" Review of Economics and Statistics 90, 216-240.

Kilian, Lutz, 2009, "Not All Oil Price Shocks Are Alike: Disentangling Demand and Supply Shocks in the Crude Oil Market," American Economic Review, 99, 1053-1069.

Kilian, Lutz and Bruce Hicks, 2011, "Did Unexpectedly Strong Economic Growth Cause the Oil Price Shock of 2003-2008?” Working paper, University of Michigan.

Kilian, Lutz and Robert J. Vigfusson, 2011, Are the Responses of the U.S. Economy Asymmetric in Energy Price Increases and Decreases? Quantitative Economics 2, 419-453.

Levy, Daniel, Shantanu Dutta, and Mark Bergen, 2002, "Heterogeneity in Price Rigidity: Evidence from a Case Study Using Microlevel Data," Journal of Money, Credit, and Banking 34, 197-220.

Lütkepohl, Helmut, 2005, New Introduction to Multiple Time Series Analysis. SpringerVerlag: Berlin.

Marcellino, Massimiliano, 1999, "Some Consequences of Temporal Aggregation in Empirical Analysis," Journal of Business and Economic Statistics, 17, 129-136. 
Mork, Knut Anton, 1989, “Oil and the Macroeconomy When Prices Go Up and Down: An Extension of Hamilton's Results.” Journal of Political Economy 97(3): 740-744.

Nakov, Anton and Andrea Pescatori, 2010, "Monetary Policy Tradeoffs with a Dominant Oil Producer,' Journal of Money, Credit, and Banking 42, 1-32.

Ramey, Valerie A., 2009, "Identifying Government Spending Shocks: It's All in the Timing," Quarterly Journal of Economics 126, 1-50.

Ramey, Valerie A. and Matthew D. Shapiro, 1998, "Costly Capital Reallocation and the Effects of Government Spending," Carnegie-Rochester Conference Series on Public Policy 48, 145-194.

Romer, Christina D. and David H. Romer, 2004, "A New Measure of Monetary Shocks: Derivation and Implications," American Economic Review 94, 1055-1084.

Romer, Christina D. and David H. Romer, 2010, “The Macroeconomic Effect of Tax Changes: Estimates Based on a New Measure of Fiscal Shocks," American Economic Review $100,763-801$.

Wu, Tao, and Andrew McCallum, 2005, "Do Oil Futures Prices Help Predict Future Oil Prices?” Economic Letter no. 2005-38, Federal Reserve Bank of San Francisco. 


\begin{tabular}{|c|c|c|c|}
\hline CODE & EVENT-TYPES & NUMBER OF DAYS & RELATIVE FREQUENCY \\
\hline 1. & U.S. weather changes & 127 & $2.12 \%$ \\
\hline 2. & Non-U.S. weather changes & 6 & $0.10 \%$ \\
\hline 3. & $\begin{array}{l}\text { Oil production/transportation disruptions in the U.S., } \\
\text { e.g., refinery explosions, etc. }\end{array}$ & 248 & $4.15 \%$ \\
\hline 4. & $\begin{array}{l}\text { Oil production/transportation disruptions not in the U.S., } \\
\text { natural disasters, etc. }\end{array}$ & 238 & $3.98 \%$ \\
\hline 5. & New oil field discoveries in the U.S. & 0 & $0 \%$ \\
\hline 6. & New oil field discoveries outside the U.S. & 0 & $0 \%$ \\
\hline 7. & Political developments in the Middle East & 476 & $7.98 \%$ \\
\hline 8. & Political developments in non-Middle East oil-exporting countries & 47 & $0.78 \%$ \\
\hline 9. & Political developments in other regions & 0 & $0 \%$ \\
\hline 10. & Military actions in the Middle East & 110 & $1.85 \%$ \\
\hline 11. & Military actions in non-Middle East oil-exporting countries & 2 & $0.03 \%$ \\
\hline 12. & Military actions in other regions & 0 & $0 \%$ \\
\hline 13. & $\begin{array}{l}\text { OPEC announcements on oil production plan, e.g., proposals } \\
\text { to cut back oil production, etc. }\end{array}$ & 741 & $12.41 \%$ \\
\hline 14. & Non-OPEC oil exporters' announcements on oil production plan & 121 & $2.03 \%$ \\
\hline 15. & $\begin{array}{l}\text { U.S. oil and gas inventory announcements, } \\
\text { SPR (strategic petroleum reserve) changes, etc. }\end{array}$ & 730 & $12.23 \%$ \\
\hline 16. & Non-US oil inventory announcements, etc. & 53 & $0.89 \%$ \\
\hline 17. & Changes in expectations of U.S. oil and gas inventories & 206 & $3.44 \%$ \\
\hline 18. & $\begin{array}{l}\text { Changes in U.S. oil demand related to the business cycle, } \\
\text { improvements in oil usage efficiency, technology, etc. }\end{array}$ & 31 & $0.51 \%$ \\
\hline 19. & $\begin{array}{l}\text { Changes in non-U.S. oil demand related to the business cycle, } \\
\text { improvements in oil usage efficiency, technology, etc. }\end{array}$ & 30 & $0.51 \%$ \\
\hline 20. & Other oil product price movements (gasoline, heating oil, etc) & 118 & 1.98 \\
\hline 21. & $\begin{array}{l}\text { Technical reasons, speculations on the oil market, } \\
\text { e.g., short covering for certain contracts, etc. }\end{array}$ & 826 & $13.83 \%$ \\
\hline 22. & No particular reason & 941 & $15.75 \%$ \\
\hline 23. & Information not available & 921 & $15.42 \%$ \\
\hline TOTAL & & 5,971 & $100 \%$ \\
\hline
\end{tabular}


Table 2. Test of the Exogeneity of Oil-Shock Series

BASELINE DEFINITION

\begin{tabular}{|c|c|c|}
\hline \multicolumn{3}{|c|}{ GRANGER CAUSALITY TESTS } \\
\hline & Log-price change & Predicting errol \\
\hline \multicolumn{3}{|l|}{ Individual Granger causality tests: } \\
\hline Real GDP & 0.5511 & 0.7500 \\
\hline $\mathrm{CPI}$ & 0.2108 & 0.4310 \\
\hline Federal funds rate & 0.8797 & 0.7993 \\
\hline PPI crude petroleum & 0.6745 & 0.0258 \\
\hline \multicolumn{3}{|l|}{ Joint Granger causality test: } \\
\hline All four variables & 0.3628 & 0.0578 \\
\hline \multicolumn{3}{|c|}{ STRONG EXOGENEITY TEST } \\
\hline $\begin{array}{l}\text { Zero coefficients and zero correlations } \\
p \text {-value }\end{array}$ & 0.1035 & 0.1910 \\
\hline
\end{tabular}

Note: Table 2 reports the $p$-value of Granger causality test, with the null hypothesis that the endogenous VARX variables have zero coefficients in the equation of oil-shock series $O_{t}$. 
Table 3. Robustness and stability checks

\begin{tabular}{|c|c|c|c|c|c|c|c|c|c|}
\hline & \multicolumn{3}{|c|}{ Market-information based } & \multicolumn{3}{|c|}{ Symmetric VAR-based } & \multicolumn{3}{|c|}{ Asymmetric VAR-based } \\
\hline & Output & Price & Interest rate & Output & Price & Interest rate & Output & Price & Interest rate \\
\hline $\begin{array}{l}\text { Baseline estimates } \\
\text { Subsamples }\end{array}$ & -6.75 & 0.14 & -0.11 & -2.91 & 0.05 & -0.07 & -1.66 & 0.04 & -0.04 \\
\hline 1984-1994 & -3.33 & -0.11 & -0.10 & 0.48 & -0.04 & 0.01 & -4.22 & -0.24 & -0.21 \\
\hline $1995-2007$ & -2.44 & 0.14 & 0.17 & -2.68 & 0.07 & -0.01 & 3.61 & 0.10 & 0.34 \\
\hline
\end{tabular}

Note: Table 3 reports the 24-month cumulative effects of different oil-price shock measures. For comparison, the shock magnitudes are normalized so that the largest response of the real oil price is 10 percent. The columns under the heading "Output" display the 24-month cumulative output loss; The columns under the "Price" and "Interest rate" headings display the 24-month cumulative changes in the CPI and the federal funds rate divided by 24 , which capture, respectively, the average increment in the CPI and the average monetary policy response over the two years after the shock. 
This page intentionally left blank

CInternational Monetary Fund. Not for Redistribution 
This page intentionally left blank

CInternational Monetary Fund. Not for Redistribution 
Figure 1: MARKET-BASED AND VAR-BASED MEASURES OF OIL SHOCKS

A. Market based measures: Predicting error

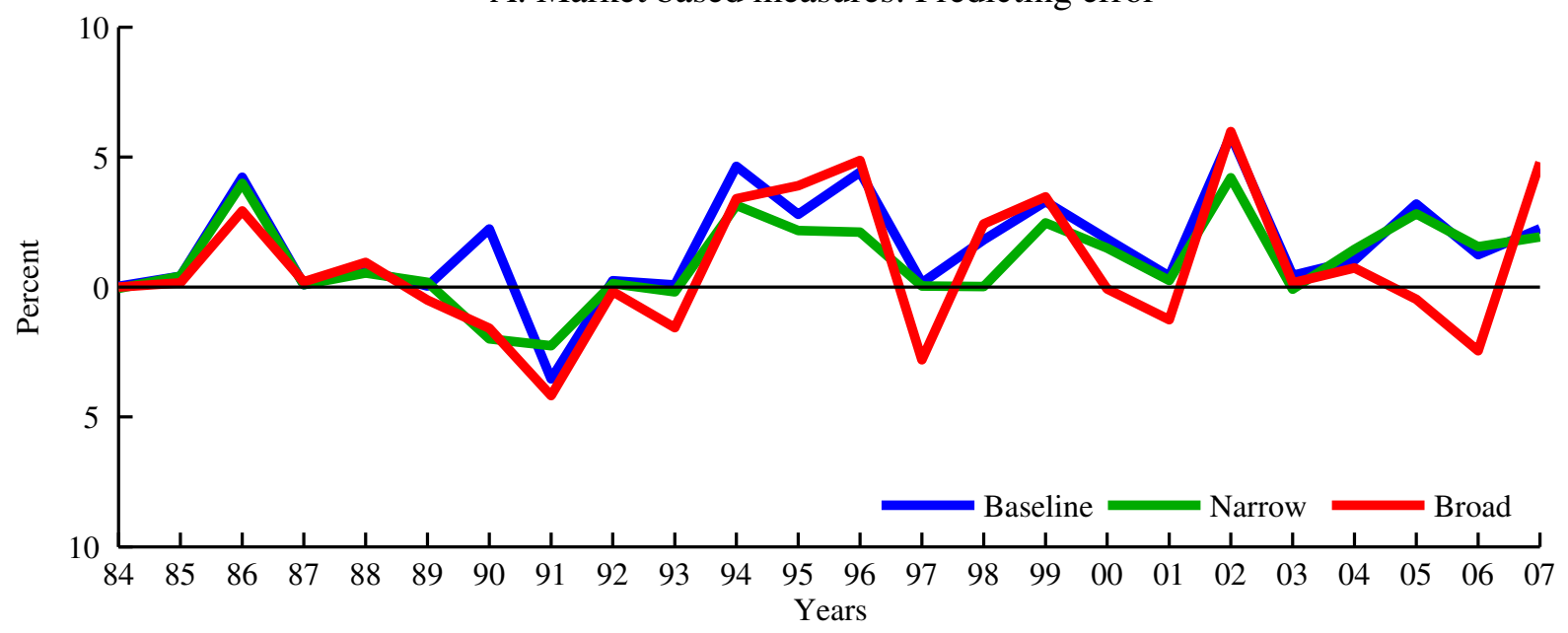

B. Market based measures: Log price change

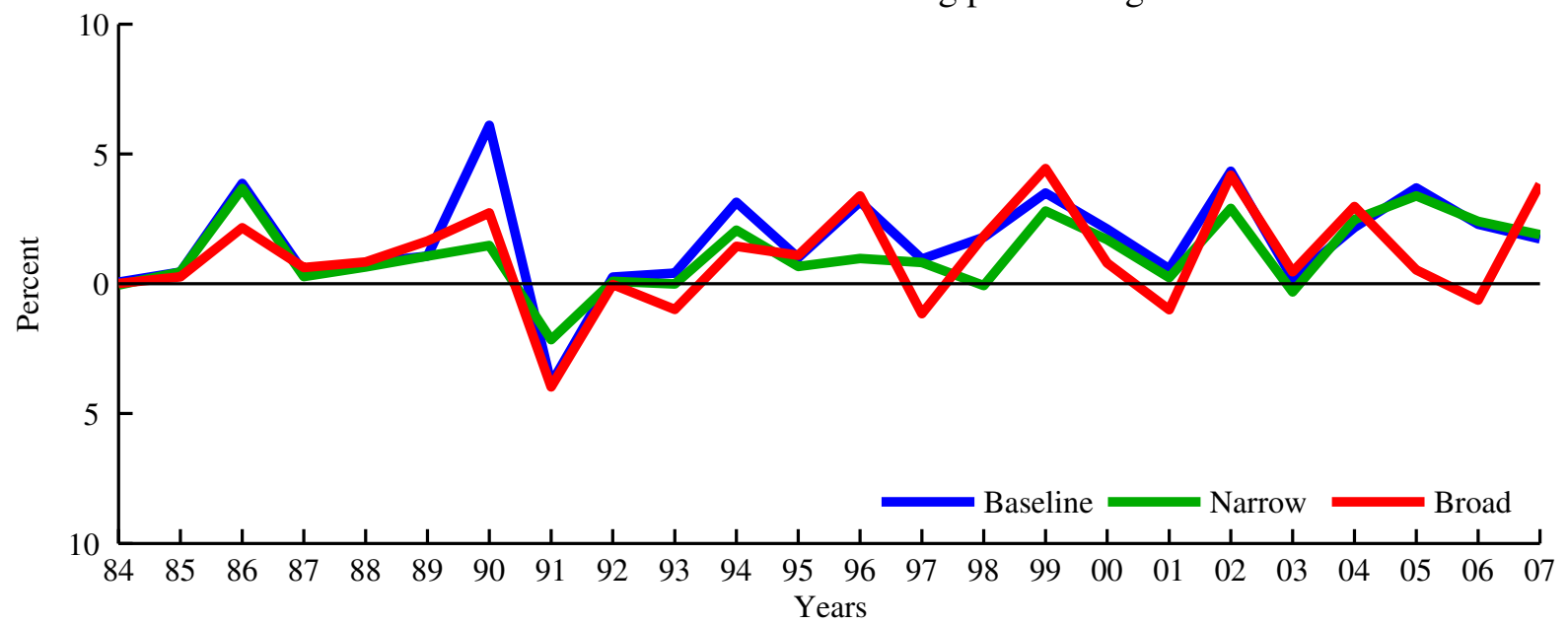

C. VAR based measures

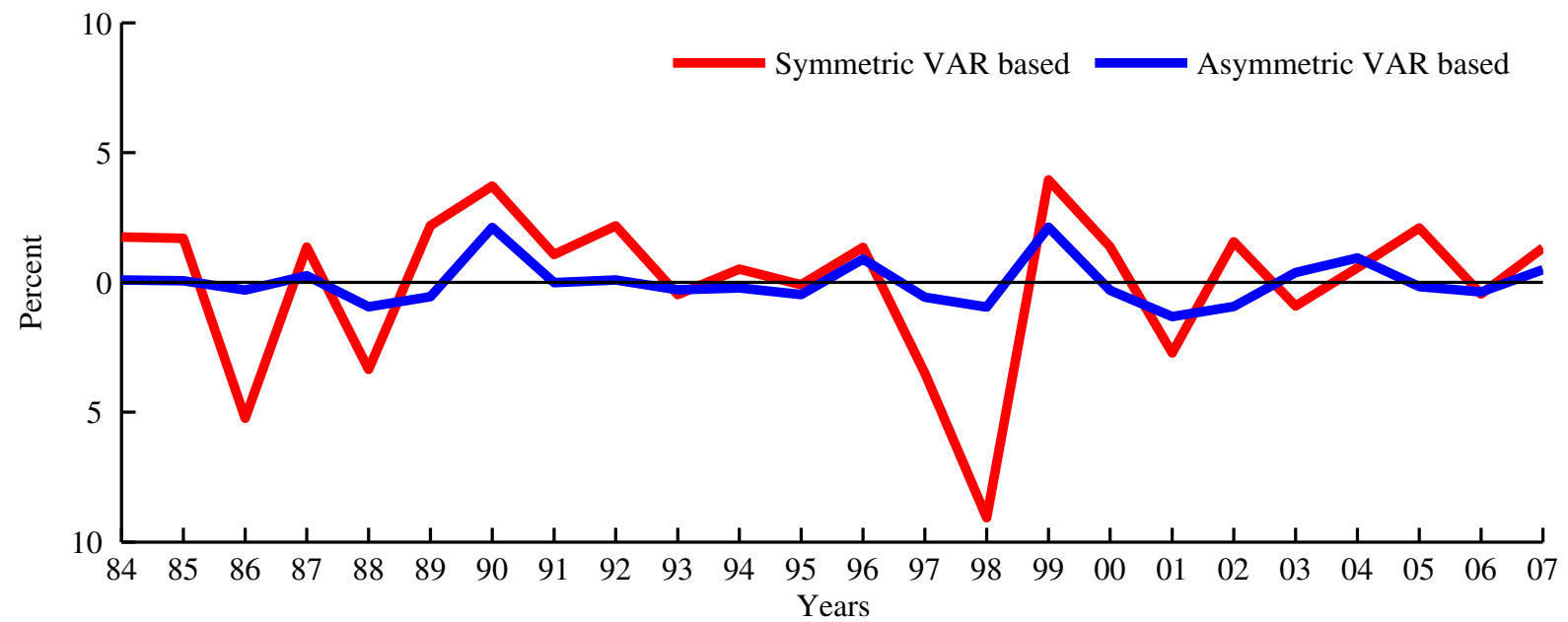

Note: Monthly shock series averaged to annual frequency. 
Figure 2: ALternative MEASURES OF EXOGENOUS OIL SHOCKS
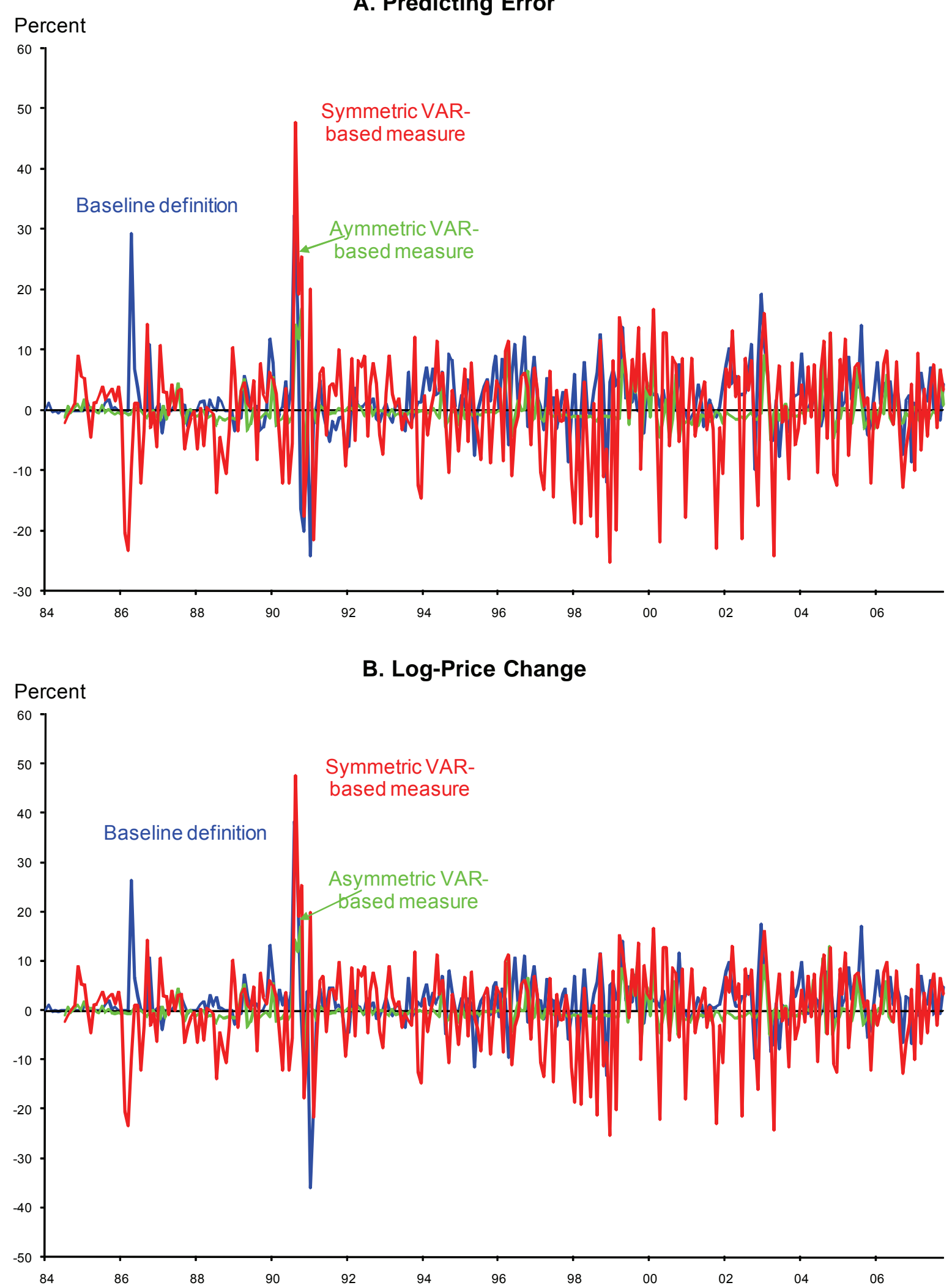
Figure 3: IMPULSE RESPONSES TO EXOGENOUS OIL-PRICE SHOCKS BASELINE DEFINITION OF EXOGENEITY

Figure 3A: Baseline Definition of Exogeneity

Log price change

GDP

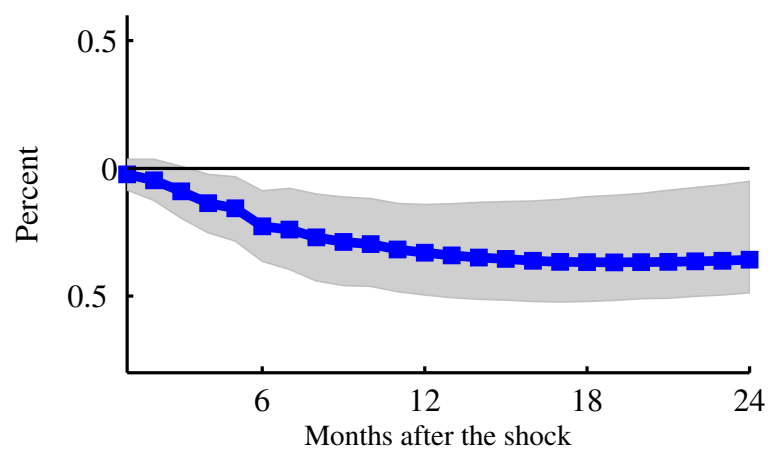

CPI

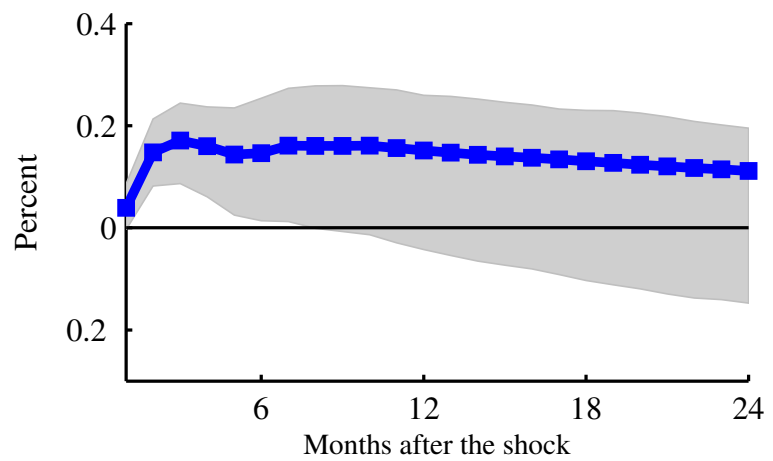

Federal Funds Rate

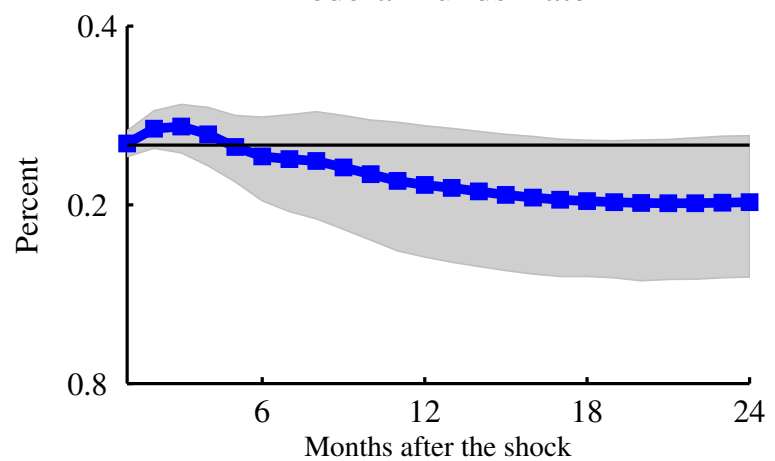

PPI Crude petroleum

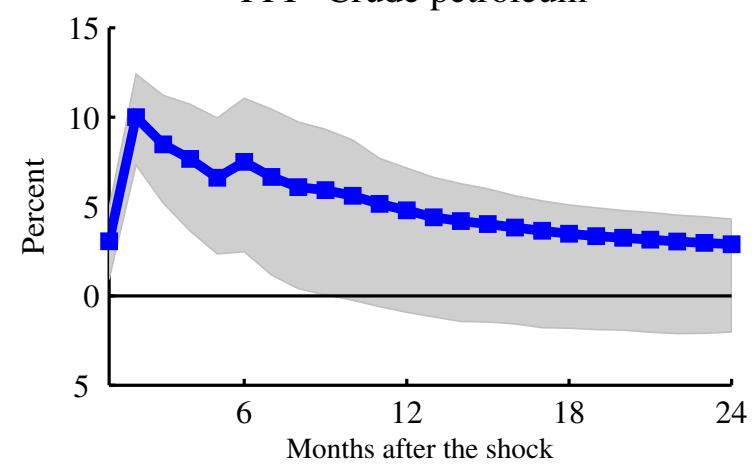

Predicting error

GDP

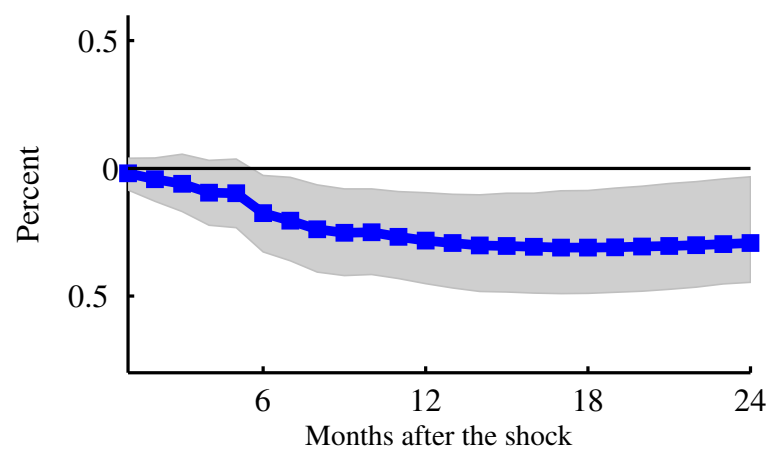

CPI

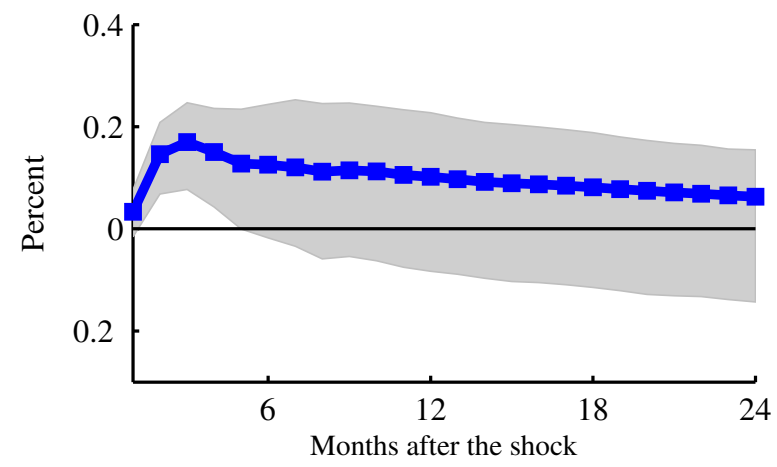

Federal Funds Rate

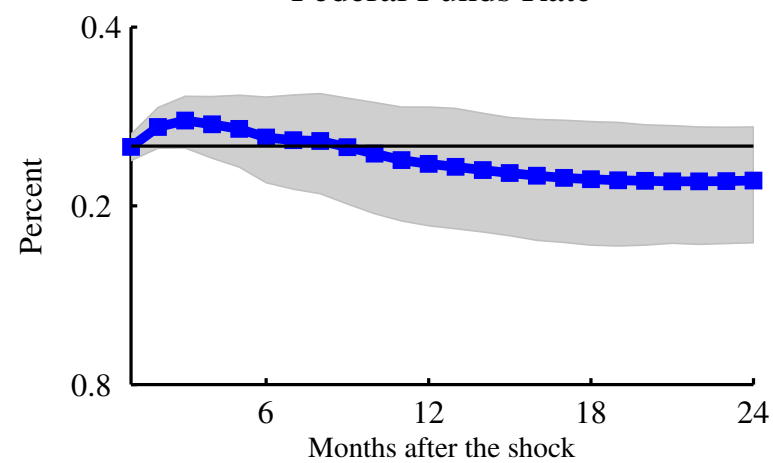

PPI Crude petroleum

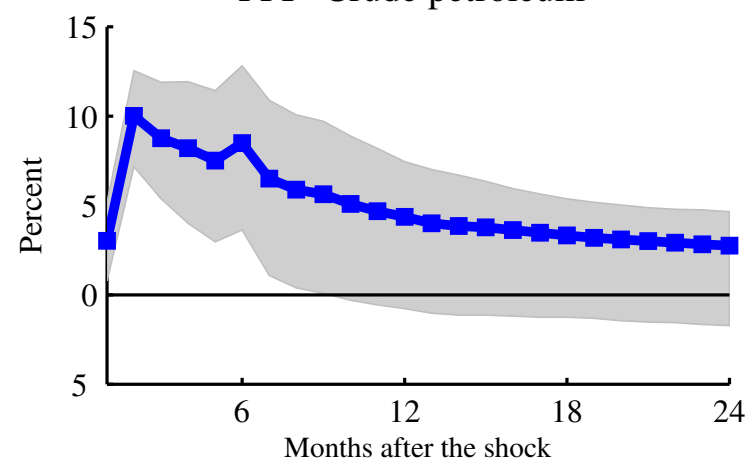


Figure 4: VAR Based Measures

Asymmetric VAR based measure

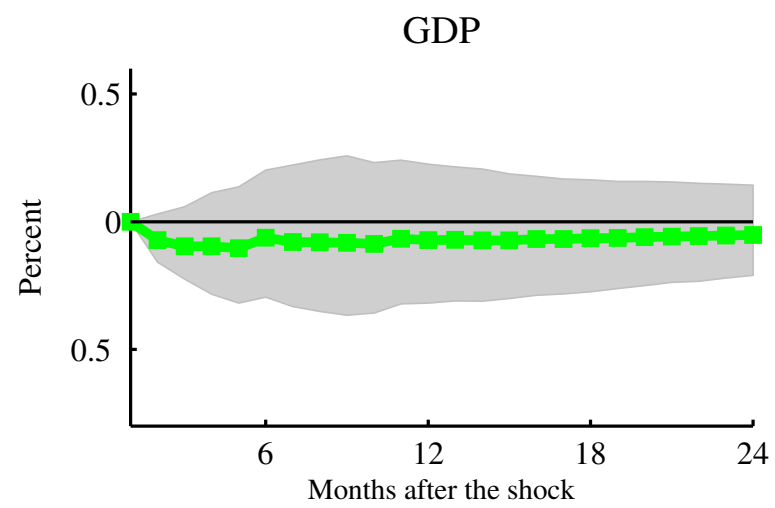

CPI

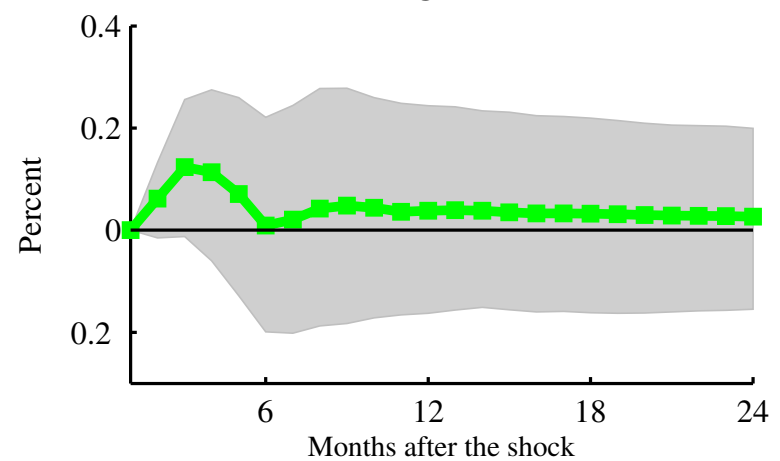

Federal Funds Rate

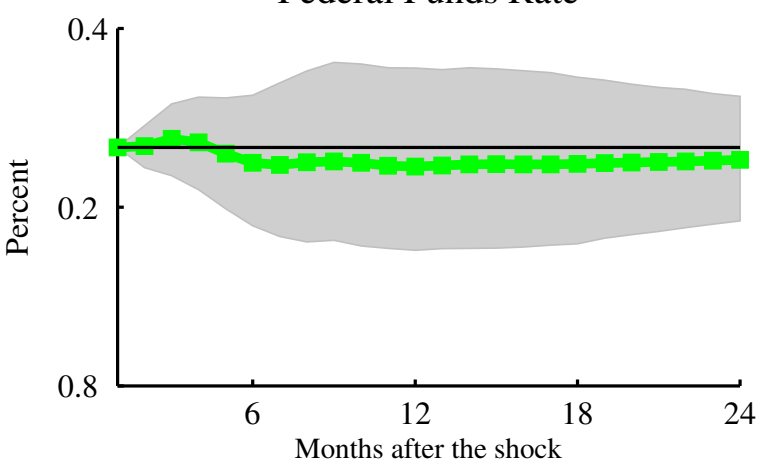

PPI Crude petroleum

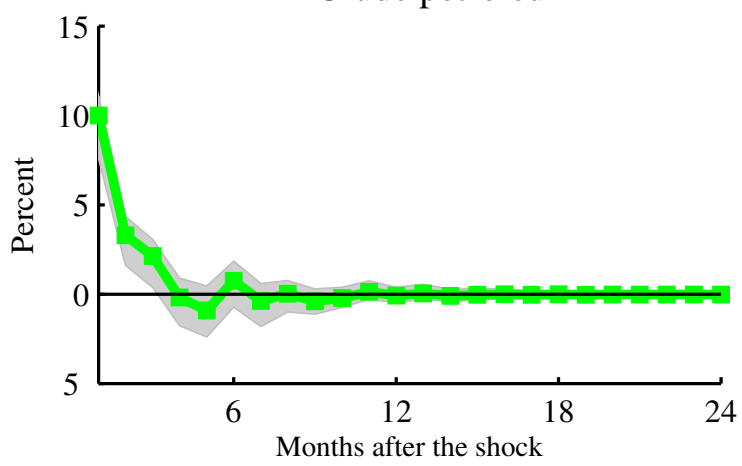

Symmetric VAR based measure

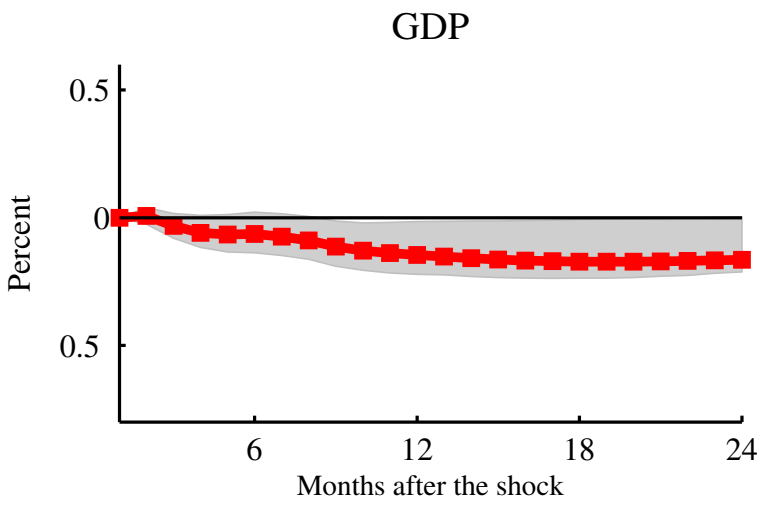

CPI

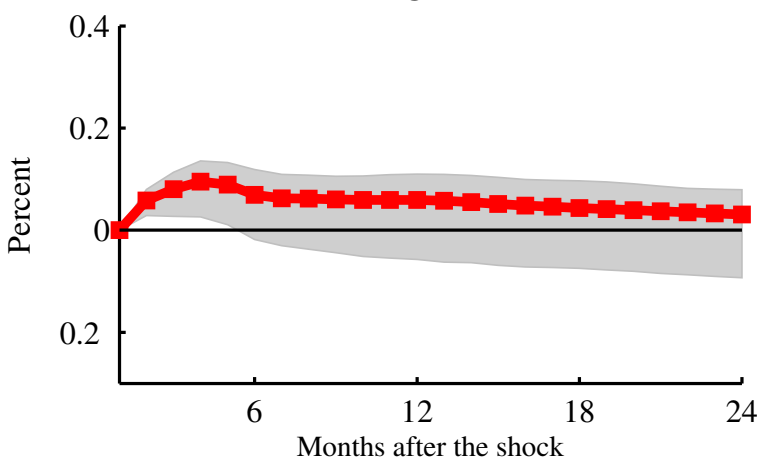

Federal Funds Rate

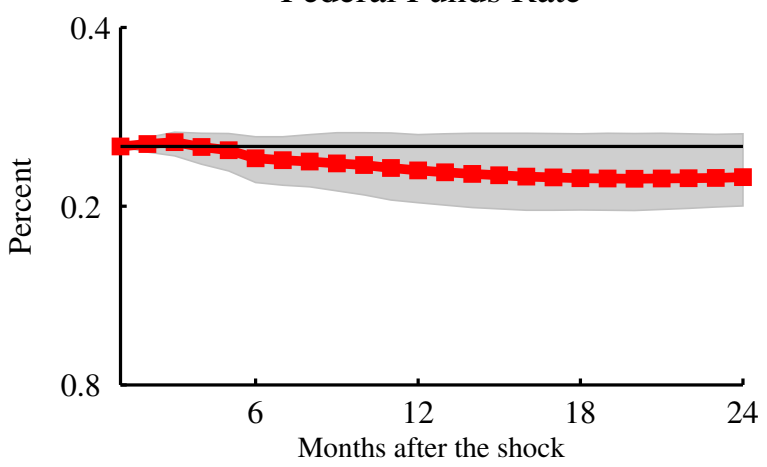

PPI Crude petroleum

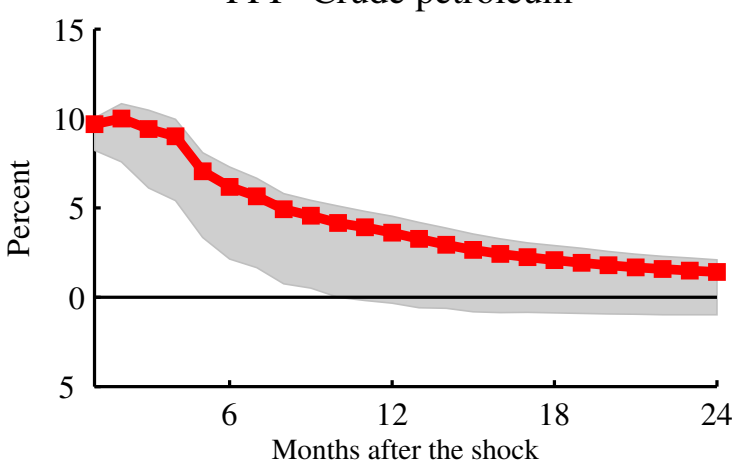


Figure 5: Alternative Estimates of Impulse Responses

Log price change

GDP

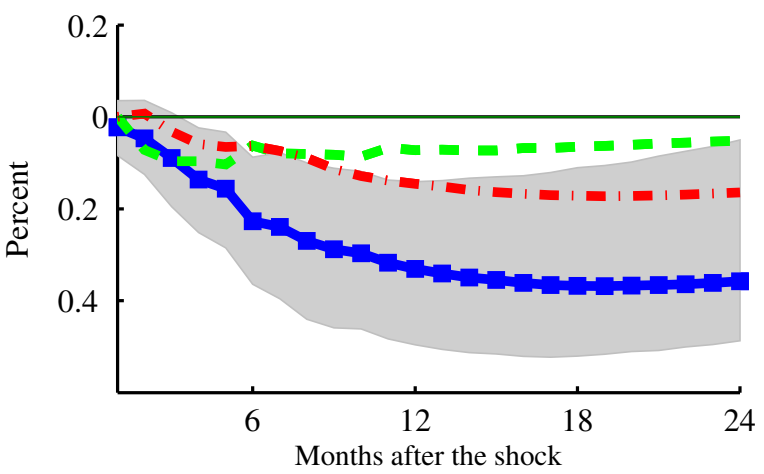

CPI

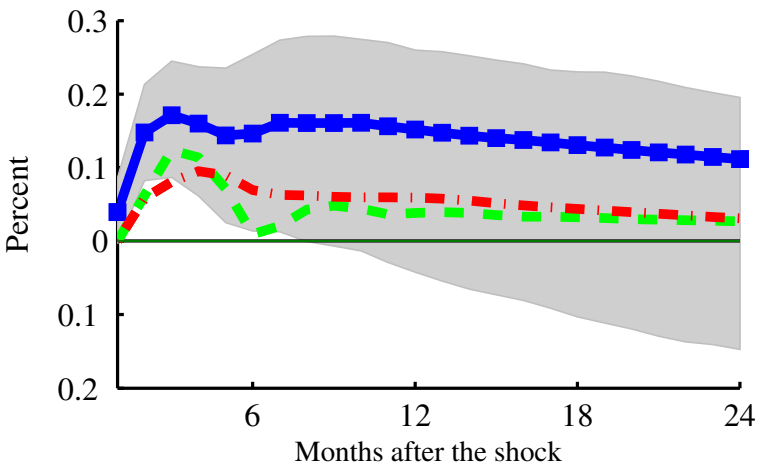

Federal Funds Rate
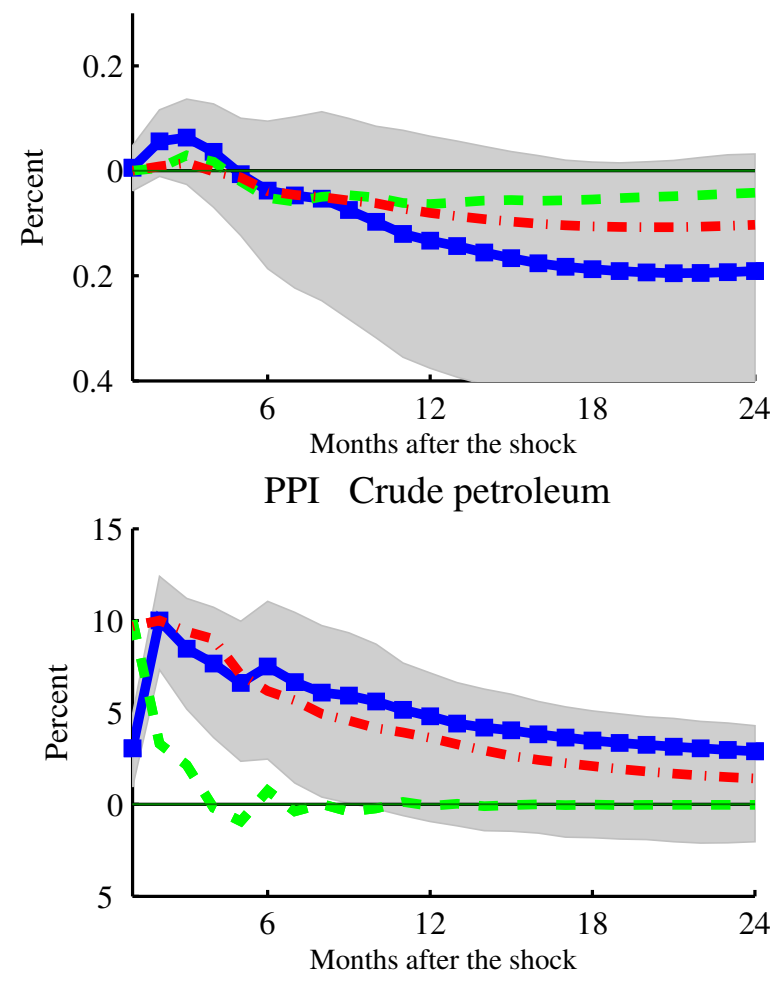

Predicting error

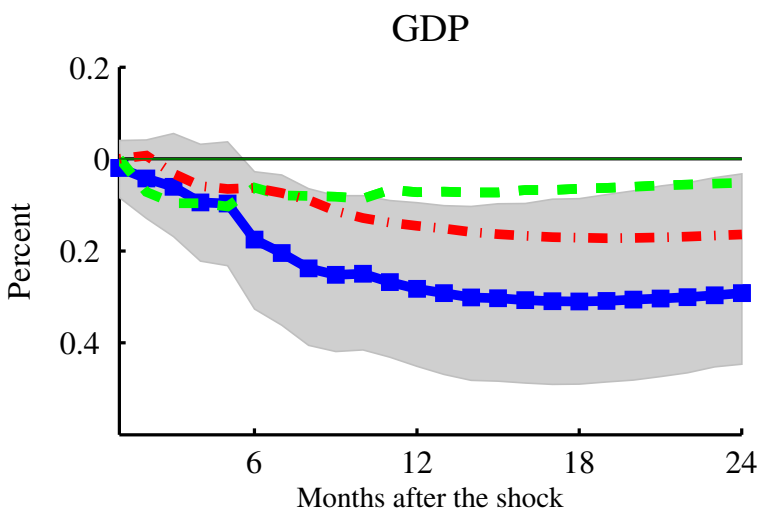

CPI
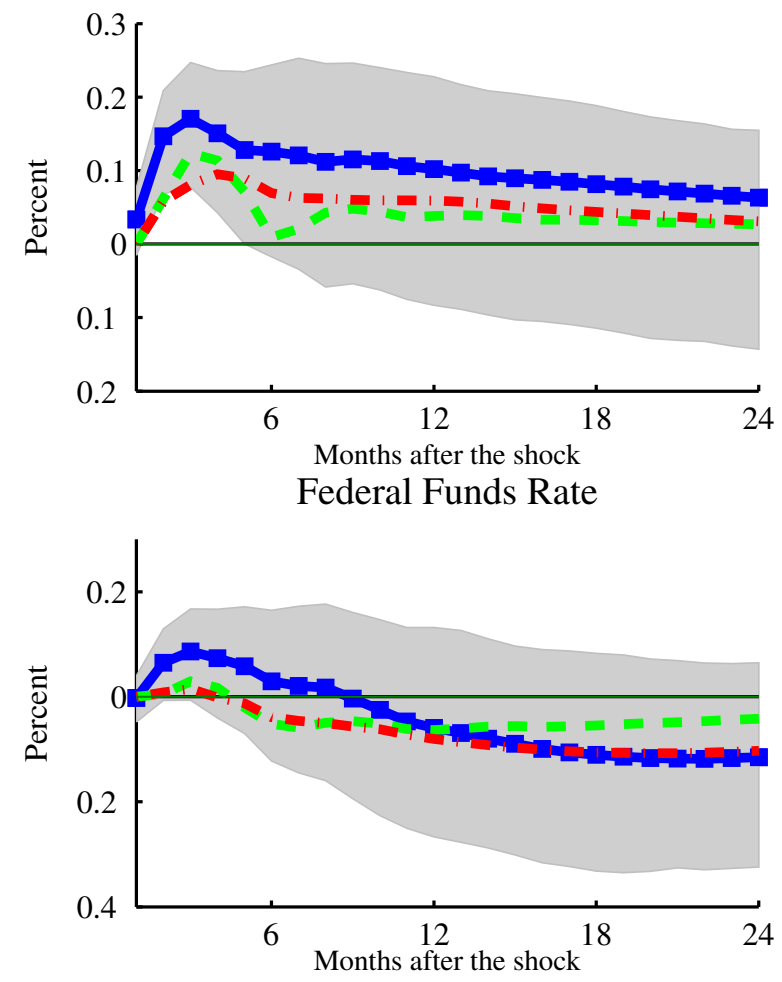

PPI Crude petroleum

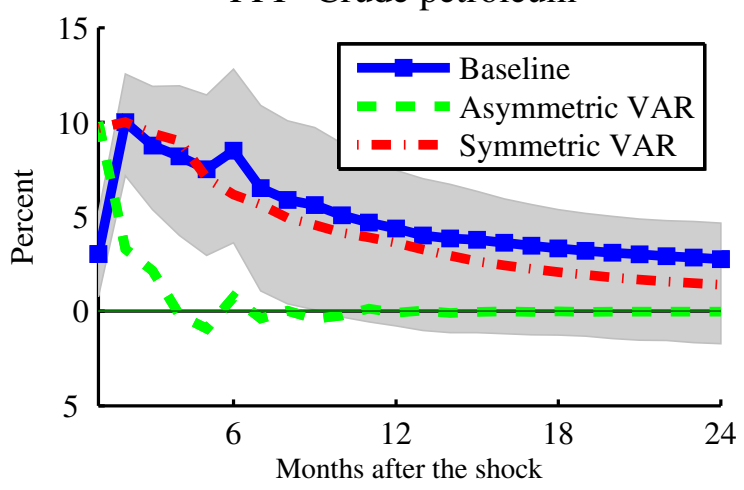


Figure 6: Impulse Responses to Oil Demand Changes

Log price change

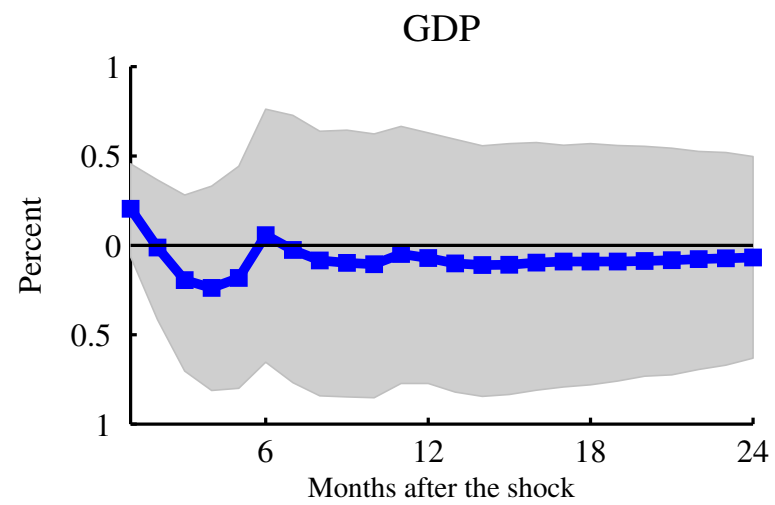

CPI

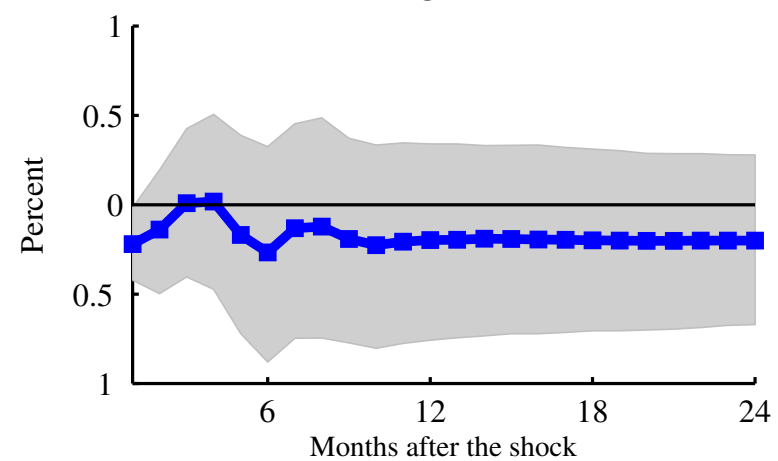

Federal Funds Rate

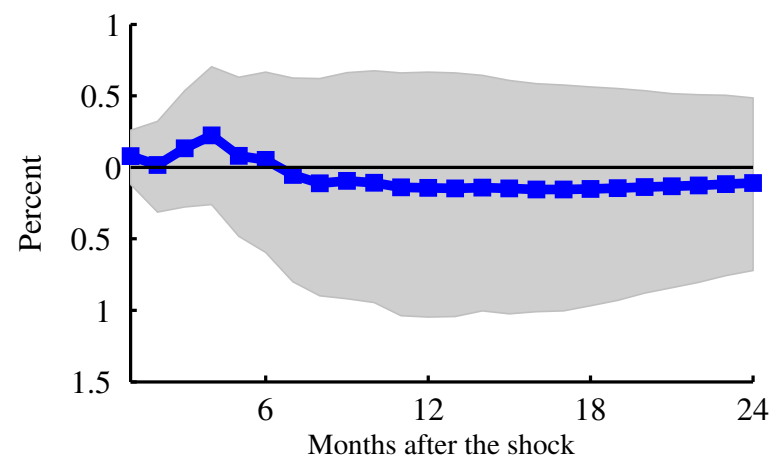

PPI Crude petroleum

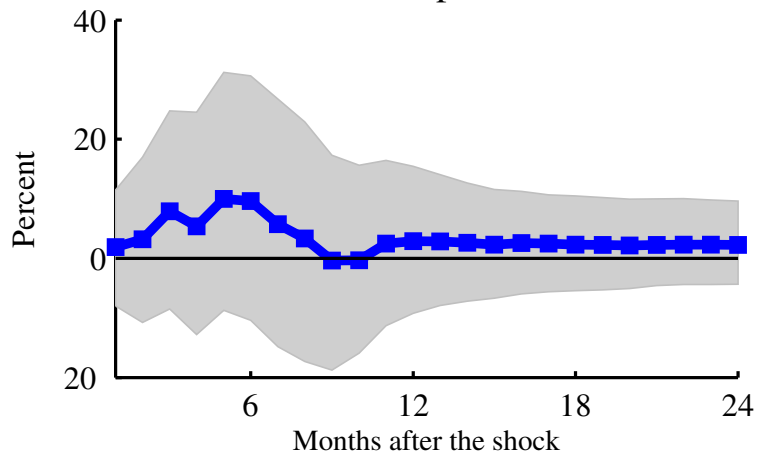

Predicting error

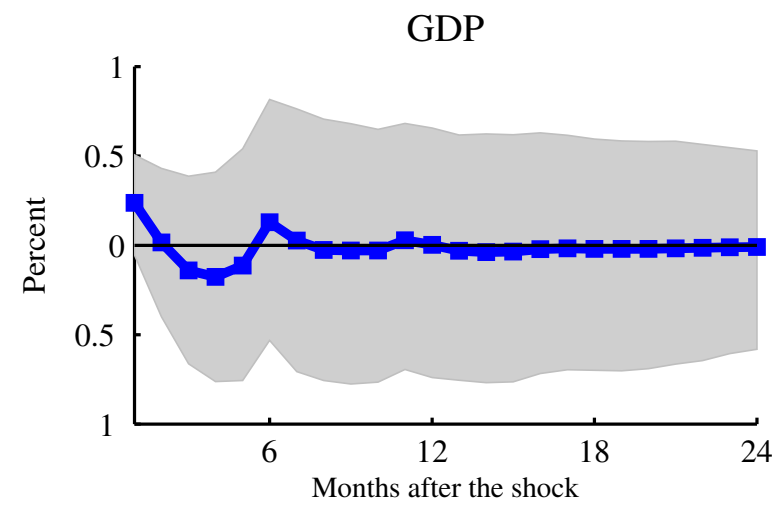

CPI

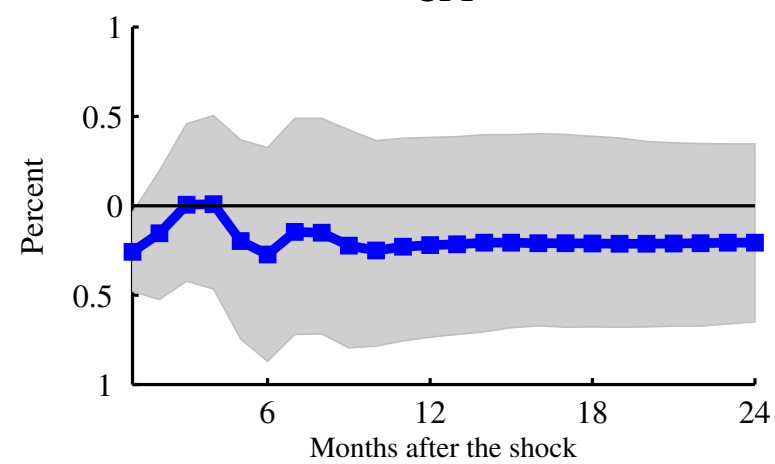

Federal Funds Rate

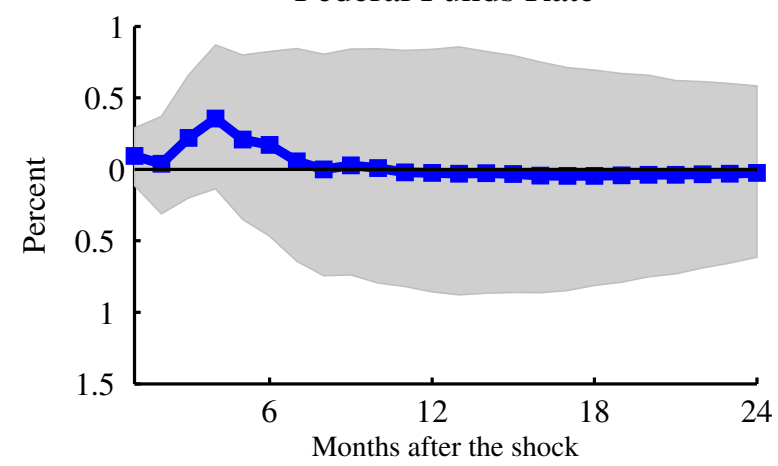

PPI Crude petroleum

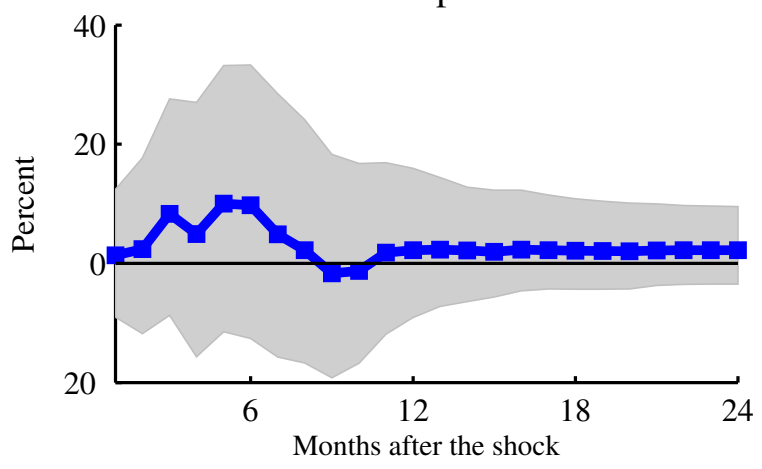


Figure 7: Impulse Responses to OPEC/Non OPEC Moves

Log price change

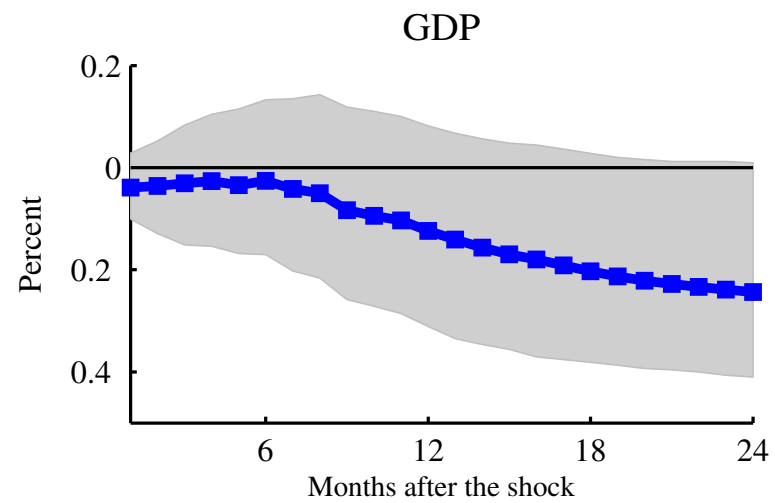

CPI

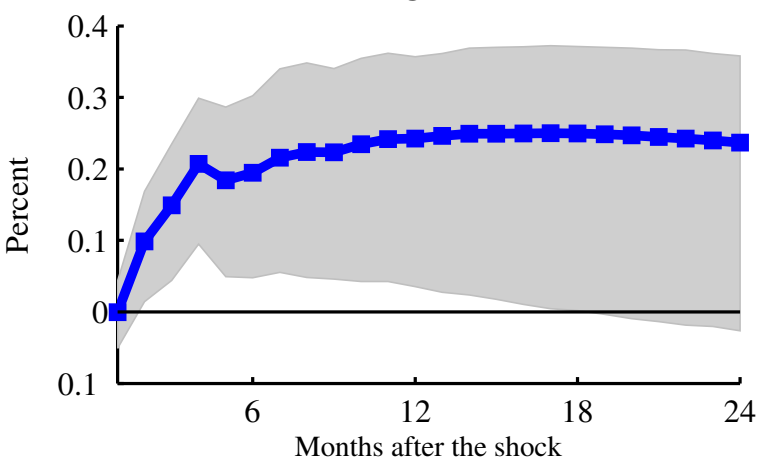

Federal Funds Rate

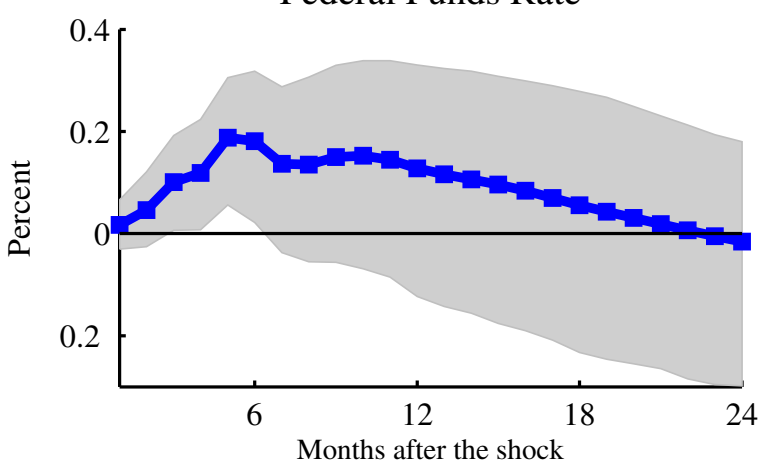

PPI Crude petroleum

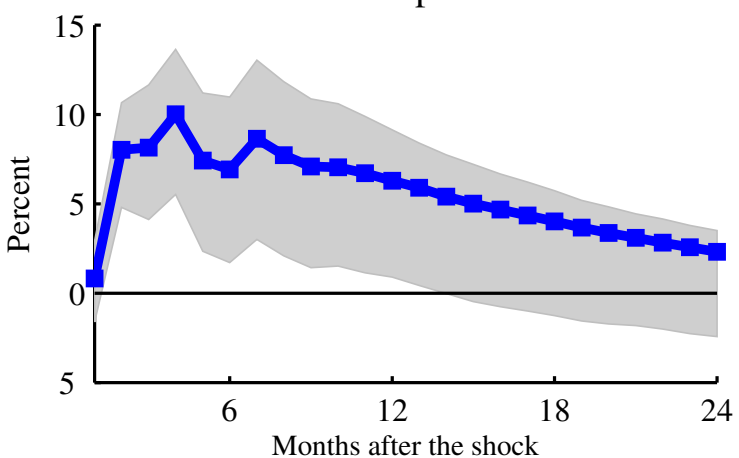

Predicting error

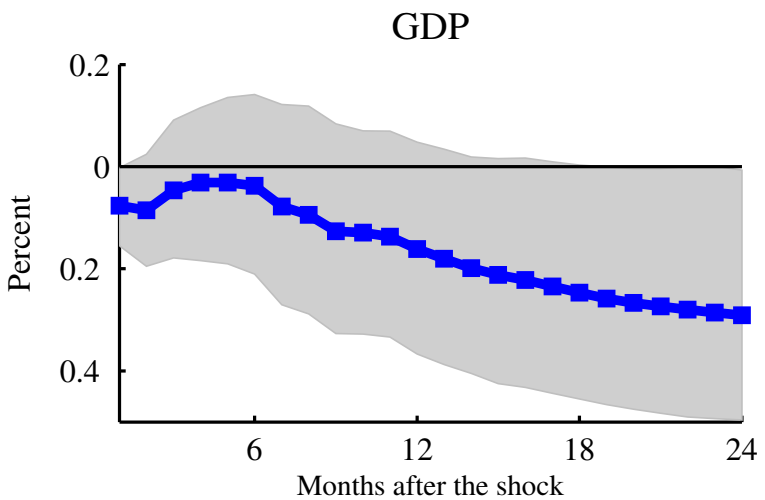

CPI

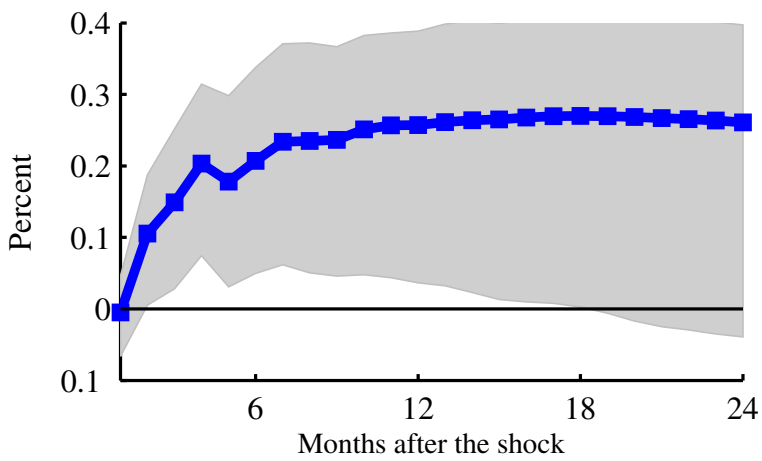

Federal Funds Rate

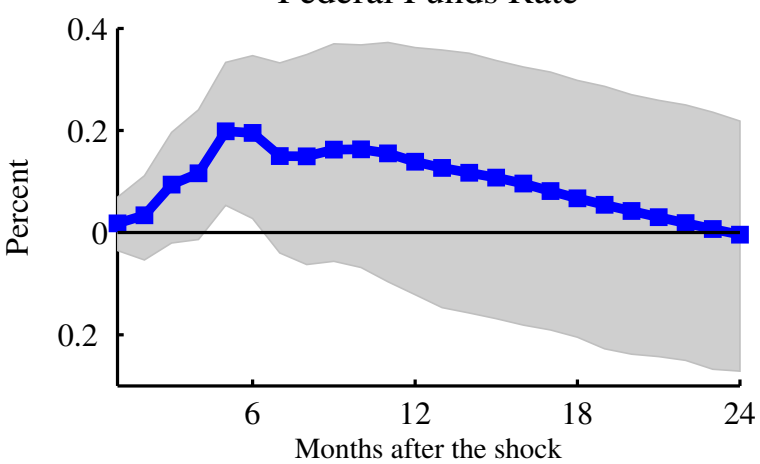

PPI Crude petroleum

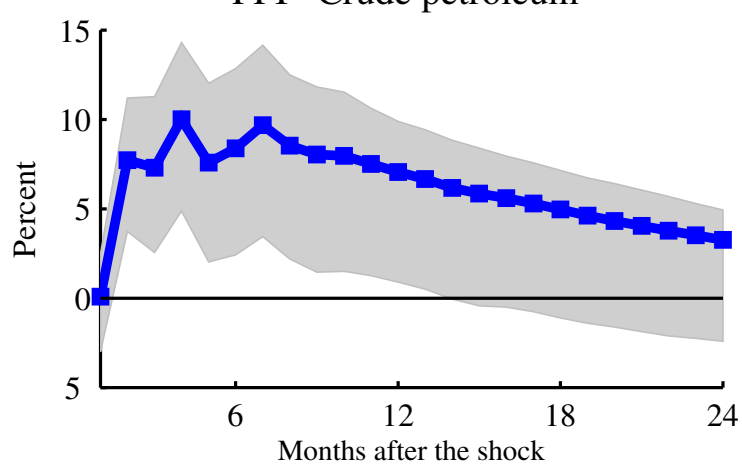


Figure 8: Impulse Responses to Oil Inventory Changes

Log price change

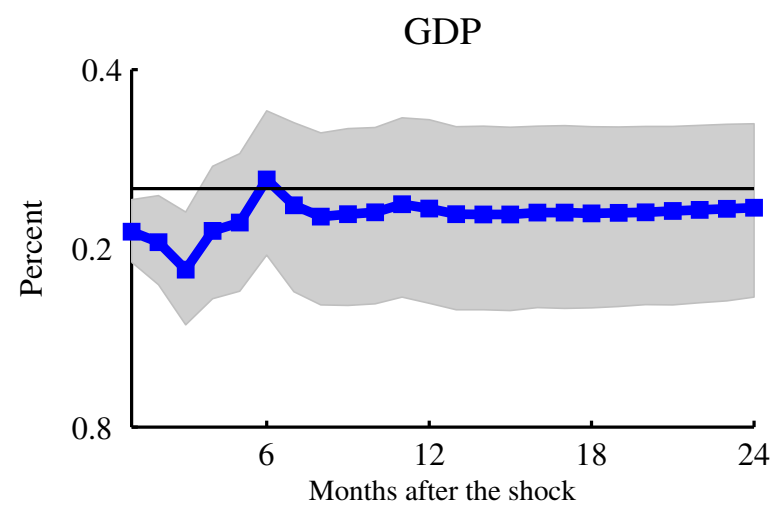

CPI

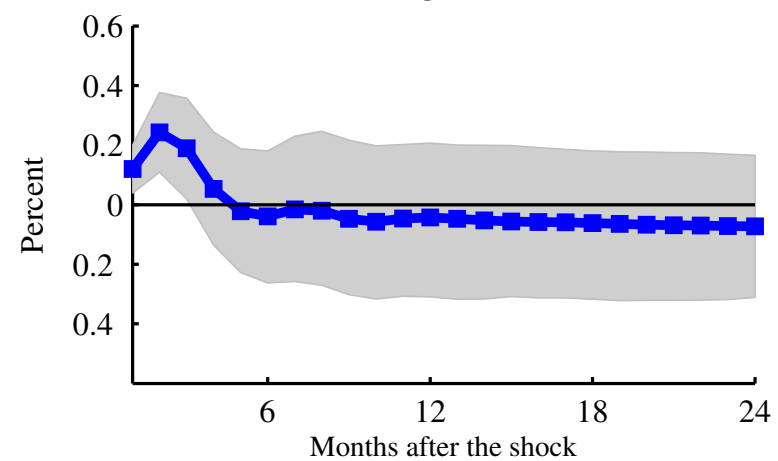

Federal Funds Rate

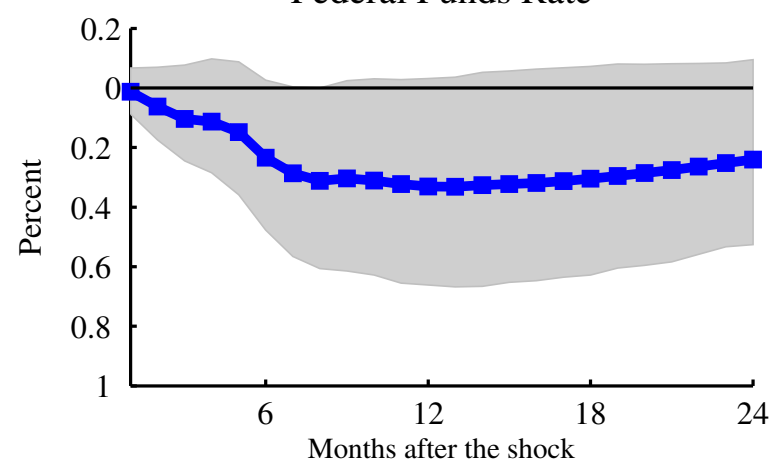

PPI Crude petroleum

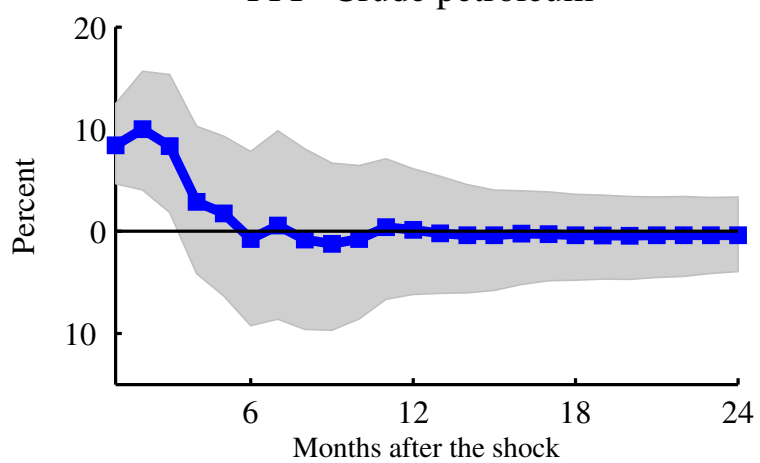

Predicting error

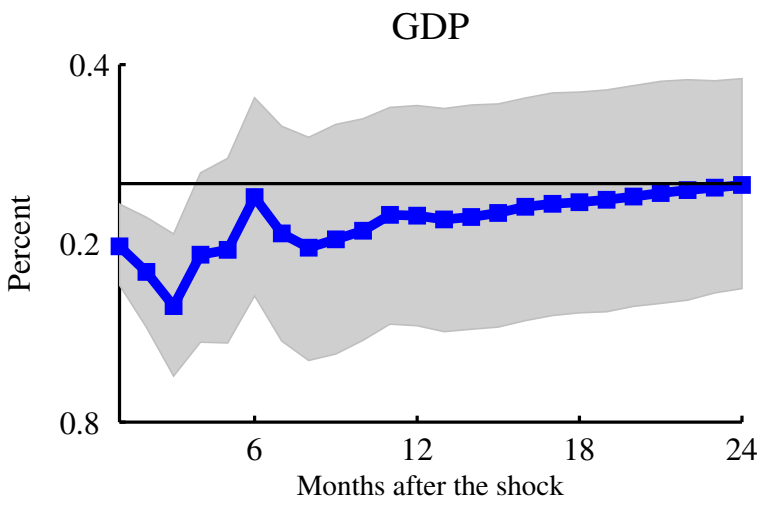

CPI

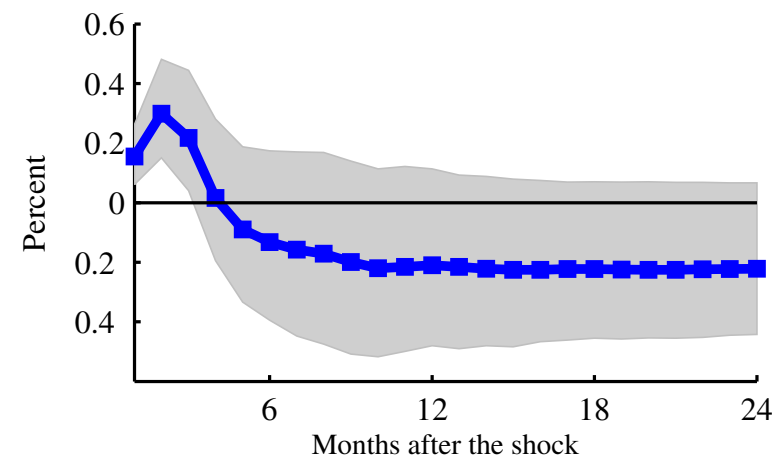

Federal Funds Rate

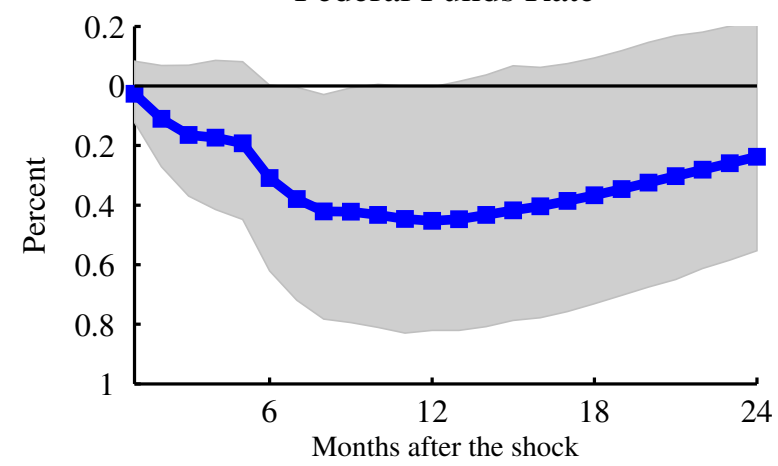

PPI Crude petroleum

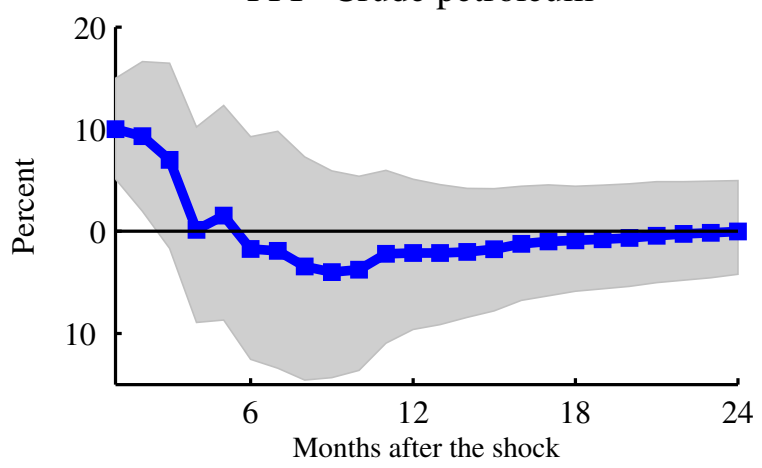


Figure 9: Impulse Responses to Military Conflicts

Log price change

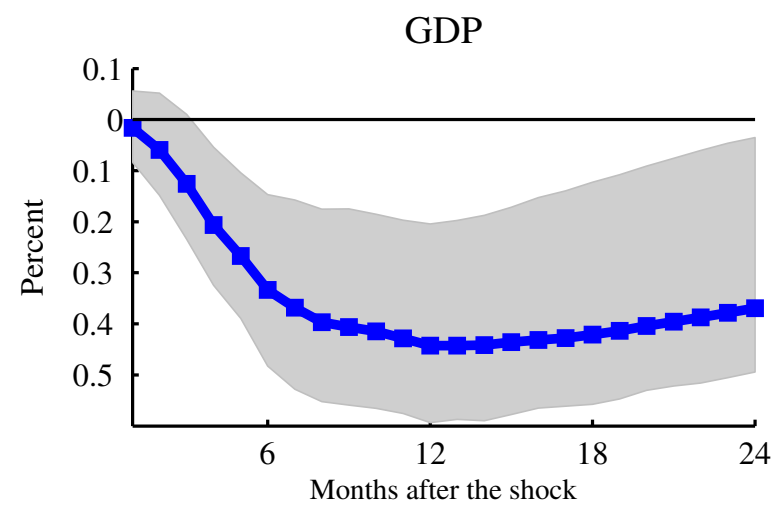

CPI

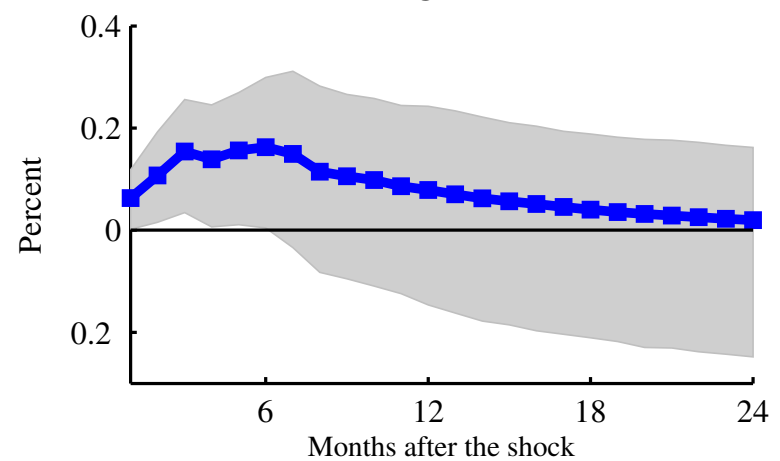

Federal Funds Rate

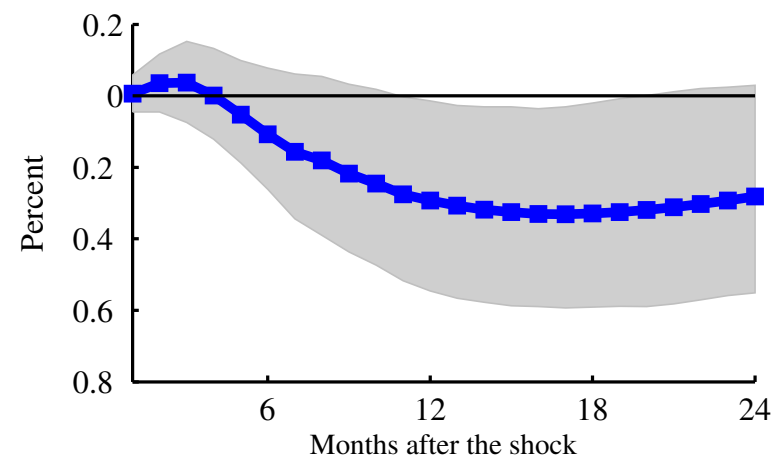

PPI Crude petroleum

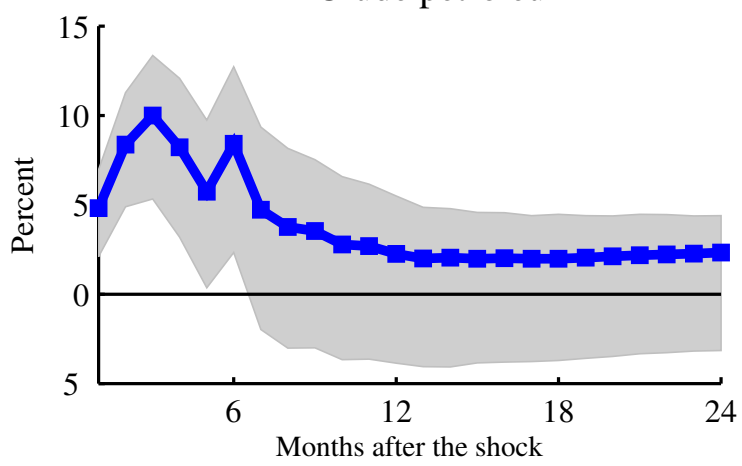

Predicting error

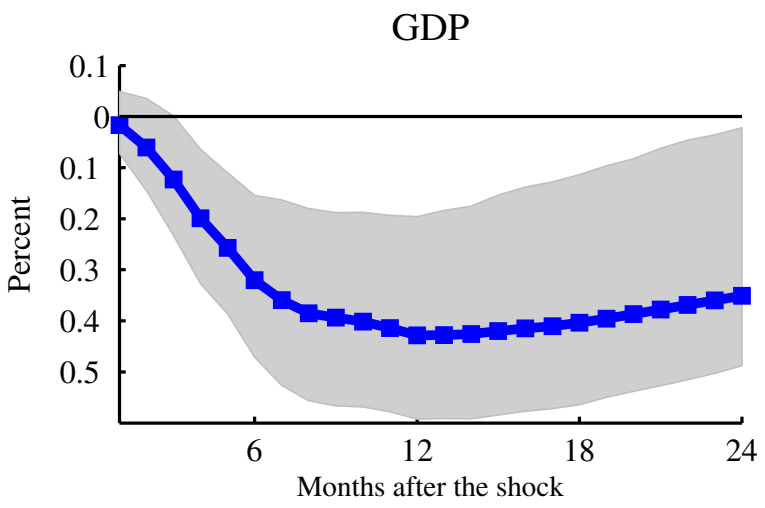

CPI

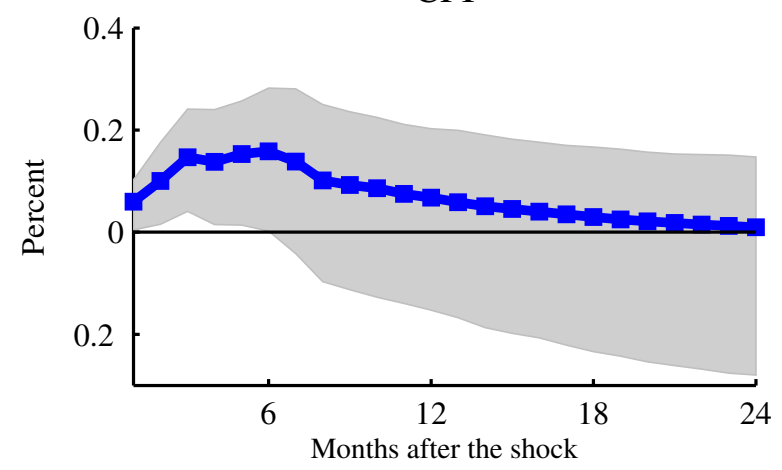

Federal Funds Rate

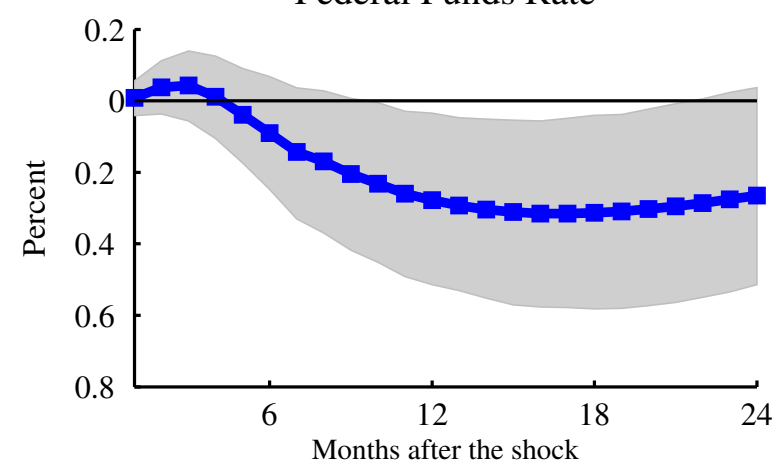

PPI Crude petroleum

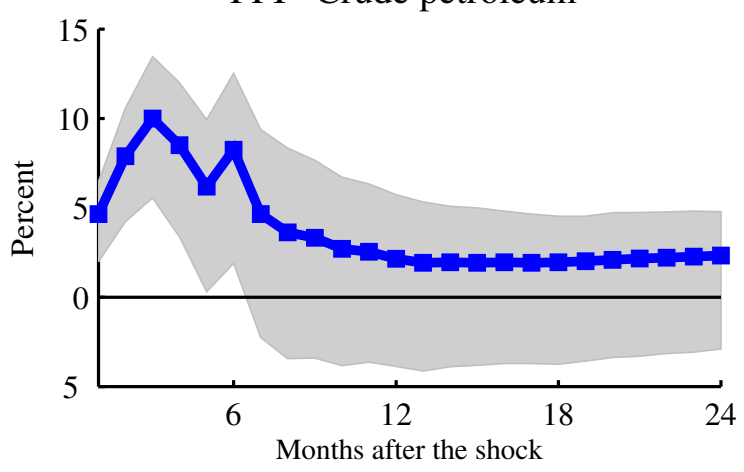


Figure 10: Impulse Responses in Sub sample Periods
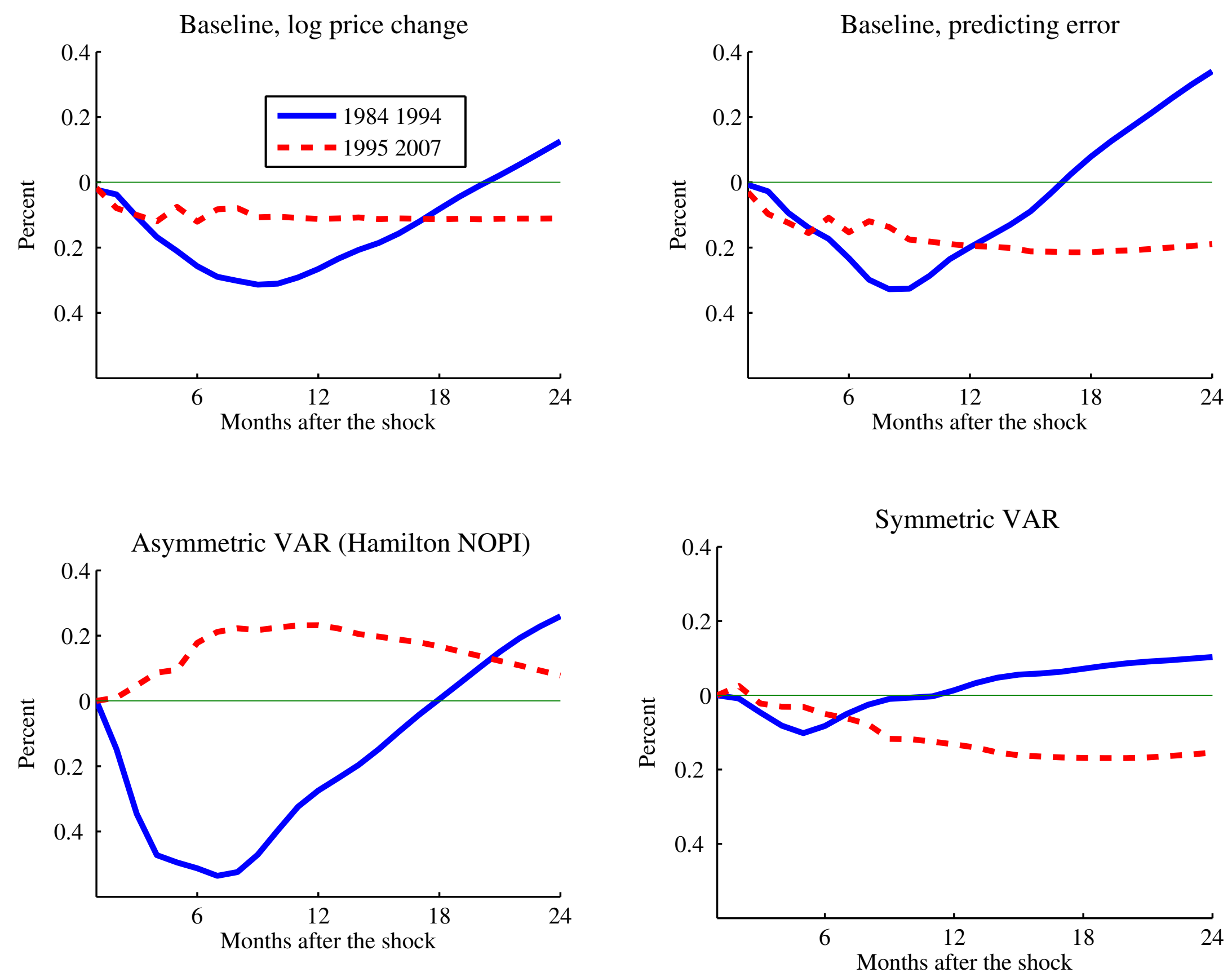

CInternational Monetary Fund. Not for Redistribution 